\title{
Modulation of Acetylation: Creating a Pro-survival and Anti-Inflammatory Phenotype in Lethal Hemorrhagic and Septic Shock
}

\author{
Yongqing Li and Hasan B. Alam \\ Department of Surgery, Division of Trauma, Emergency Surgery and Surgical Critical Care, Massachusetts General Hospital/Harvard \\ Medical School, 165 Cambridge Street, Suite 810, Boston, MA 02114, USA \\ Correspondence should be addressed to Hasan B. Alam, hbalam@partners.org
}

Received 20 July 2010; Accepted 16 November 2010

Academic Editor: Patrick Matthias

Copyright ( $) 2011$ Y. Li and H. B. Alam. This is an open access article distributed under the Creative Commons Attribution License, which permits unrestricted use, distribution, and reproduction in any medium, provided the original work is properly cited.

Histone deacetylases (HDACs) play a key role in homeostasis of protein acetylation in histone and nonhistone proteins and in regulating fundamental cellular activities. In this paper we review and discuss intriguing recent developments in the use of histone deacetylase inhibitors (HDACIs) to combat some critical conditions in an animal model of hemorrhagic and septic shock. HDACIs have neuroprotective, cardioprotective, renal-protective, and anti-inflammatory properties; survival improvements have been significantly shown in these models. We discuss the targets and mechanisms underlying these effects of HDACIs and comment on the potential new clinical applications for these agents in the future. This paper highlights the emerging roles of HDACIs as acetylation modulators in models of hemorrhagic and septic shock and explains some contradictions encountered in previous studies.

\section{Introduction}

Hemorrhagic shock (HS) is a major cause of morbidity and mortality among trauma patients. Sepsis or septic shock is a leading cause of mortality in intensive care units. Even if some patients with HS survive the acute episode of blood loss, they often exhibit a systemic inflammatory response syndrome (SIRS), which is often further complicated by the subsequent development of septic shock resulting from a harmful or damaging host response to infection [1]. HSinduced systemic response shares many features with septic response [2]. At the molecular level, it has been reported that both hemorrhage and sepsis lead to an imbalance in acetylation of proteins and that HDACIs can induce protein acetylation and restore this balance [3-5].

1.1. Lysine Acetylation and Histone Deacetylase Inhibitors. Lysine acetylation or $\mathrm{N}^{\varepsilon}$-acetylation, identified initially on core histones in 1968 [6], is mediated by a group of enzymes called histone acetyltransferases (HATs) that transfer acetyl groups from acetyl-coenzyme A to the $\varepsilon$-amino group of lysines. HATs are counterbalanced by the activity of histone deacetylases (HDACs) that catalyze the hydrolytic removal of acetyl group of lysines. In humans, HDACs are divided into four classes (Table 1) based on their homology to yeast HDACs $[7,8]$. Class I HDACs include HDAC1, 2, 3, and 8; these are related to the yeast enzyme Rpd3. Class II HDACs include HDAC4, 5, 6, 7, 9, and 10, which are related to the yeast protein HDA1 (histone deacetylase-A1); class II HDACs are further divided into two subclasses-IIa (HDAC4, 5, 7, and 9) and IIb (HDAC6 and 10)-according to their structural similarities. Class III HDACs are referred to as sirtuins owing to their homology to the yeast HDAC Sir2. This class includes SIRT1-SIRT7 $[9,10]$. HDAC11, the most recently identified isoform, is a class IV HDAC due to its distinct structure [11]. Class I, II, and IV are zinc-dependent enzymes whereas class III HDACs are nicotinamide adenine dinucleotide $(\mathrm{NAD}+)$-dependent enzymes. Based on their various subcellular localization, intratissue variation, and nonredundant activity, the different HDACs are implicated 
in various specific cellular processes, such as proliferation, metabolism, and differentiation. For example, class I HDACs are mainly nuclear enzymes whereas class II HDACs localize either to the cell nucleus or to the cytoplasm, depending on their phosphorylation and subsequent binding of 143-3 proteins. Moreover, class I HDACs are ubiquitously expressed [12-15] whereas class II HDACs display a tissuespecific expression.

To date, more than 15 HDACIs have been tested in preclinical and early clinical studies for cancer therapy [16]. Many of them are broad-spectrum- or pan-HDACIs which inhibit many of the Class I, II, and IV isoforms, including suberoylanilide hydroxamic acid (SAHA), trichostatin A (TSA), and valproic acid (VPA). Some clinical compounds such as MS-275, FK-228, and apicidin have been termed as "Class I-selective", since they target several Class I isoforms of HDAC. Tubacin is one of a few HDACIs that have been reported as HDAC6-specific inhibitor [18]. Suramin, a class III HDAC inhibitor for SIRT1, SIRT2, and SIRT5, is a polysulfonated polyaromatic symmetrical urea with antiproliferative and antiviral activity [17] (Table 1). So far, almost all of the studies focus on class I and class II HDACs [19], and a few focus on class III/sirtuins.

1.2. Protein Acetylation Balance. Signals that enter the cell nucleus encounter chromatin where gene expression takes place. Regulation of gene expression has two components that act in concert: alteration of chromatin structure governed by histone modification and binding by transcription factors (TFs) including activators and repressors. Most importantly, two classes of enzymes control the alteration and binding: HAT and HDAC. HAT modify core histone tails by posttranslational acetylation of specific lysine residues and create appropriate "histone code" for chromatin modification to enhance DNA accessibility of TFs. In general, acetylation of core histones unpacks the condensed chromatin and renders the target DNA accessible to transcriptional machinery, hence contributing to gene expression. In most cases, the TFs can also be acetylated by HAT to facilitate their interactions with DNA and other proteins for transactivation. By contrast, deacetylation of the histones and TFs by HDAC increases chromatin condensation and precludes binding between DNA and TFs, leading to transcriptional silencing. In normal conditions, protein concentration and enzyme activity of HAT and HDAC remain in a highly harmonized state of balance, which is named as "acetylation homeostasis" to emphasize the importance of regulated acetylation in acceding cellular homeostasis [20]. Recent studies have shown that during various neurodegenerative challenges, the balance is disturbed by loss of HAT activity while the ratio of HAT to HDAC tilts in favor of HDAC. The impaired acetylation homeostasis can cause transcriptional dysfunction and facilitate neurodegenerative cascade, which has been implicated in pathogenesis of several neurodegenerative disorders $[21,22]$. Indeed, perturbation of acetylation homeostasis is emerging as a central event in the pathogenesis of neurodegeneration. Recent studies have demonstrated HDACIs to be protective in animal models of Huntington's disease [23-26], amyotrophic lateral sclerosis
$[27,28]$, experimental autoimmune encephalitis [29], spinal muscular dystrophy [30, 31], and others [32].

Recently, HDACIs have emerged as potent prosurvival and anti-inflammatory drugs, offering new lines of therapeutic intervention for hemorrhagic shock and septic shock. We and other groups have found that HDACIs such as VPA, SAHA, and TSA prevent hemorrhage-associated lethality in a rat and swine models of hemorrhagic shock $[3,4,33]$, suppress expression of proinflammatory cytokines, and improve survival in a mouse model of septic shock $[5,34,35]$. We have also demonstrated that inhibition of HDAC can modulate the immune response following trauma/hemorrhage and inflammatory second hit in animals and humans [36]. This paper highlights the emerging roles of HDACIs as acetylation modulators in models of hemorrhagic shock and septic shock, and explains some contradictions encountered in previously published results.

\section{HDACIs in Hemorrhagic Shock}

HS represents a global ischemic stress, resulting from acute blood loss. Current treatment for HS focuses on pathophysiology at the level of organ systems: to maintain sufficient tissue perfusion and vital organ function through administration of fluids and blood products and to surgically control the source of hemorrhage. Unfortunately, this resource intensive protocol remains difficult to administer, particularly in austere environments, where advanced surgical interventions may not be immediately available [37]. Moreover, this approach fails to address much of the damage that takes place at the cellular level as a result of hypoperfusion (during hemorrhage) and reperfusion (during resuscitation) [38].

Focusing on the cellular pathophysiology of hemorrhagic shock, our laboratory has explored the strategy of pharmacologic resuscitation with HDACIs as the protective agents. HDACIs alter the acetylation status of proteins and therefore have the potential to modulate the genomic and proteomic changes induced by hemorrhage. We have shown that HDACIs can dramatically improve survival in lethal models of hemorrhagic shock in rat $[39,40]$ and swine models [41]. Moreover, these inhibitors can protect cells from apoptosis and suppress expression of proinflammatory cytokines [5, 42, and Fukudome et al., unpublished data].

The cell protective mechanisms involve (1) epigenetic regulation through post translation modification of histone proteins, (2) activation of cell survival factors such as the PI3-kinase/Akt signaling pathway, (3) blockage of gutliver/lymph-lung axis, and (4) inhibition of inflammatory mediators such as the Toll-like Receptor 4 (TLR4) signaling pathway. All of these actions directly or indirectly involve restoration of protein acetylation.

2.1. Acetylation-Related Epigenetic Regulation. Control of epigenetic regulation with induction of histone acetylation is the strategy to restore and maintain the normal ratio of HAT/HDAC for treatment of many diseases. A number of preclinical studies have demonstrated that HDACI can improve survival in degenerative diseases, prevent brain from various insults, attenuate the effects of aging, and increase 
TABLE 1: Classification of HDACs and selected HDACIs.

\begin{tabular}{|c|c|c|c|c|c|}
\hline HDAC Class & $\begin{array}{l}\text { HDAC } \\
\text { isoforms }\end{array}$ & Localization of HDAC & Specific HDAC inhibitors & Nonspecific HDAC inhibitors & References \\
\hline Class I & HDAC1 & Nucleus & MS-275, FK-228 & TSA & \multirow{4}{*}[9,16]{} \\
\hline \multirow[t]{3}{*}{$\left(\mathrm{Zn}^{++}\right.$-dependent $)$} & HDAC2 & Nucleus & FK-228, apicidin & SAHA & \\
\hline & HDAC3 & Nucleus & \multirow[t]{2}{*}{ MS-275, Apicidin } & Butyrate & \\
\hline & HDAC8 & Nucleus & & Valproic acid & \\
\hline Class IIa & HDAC4 & Nuc/Cyt & & TSA & \multirow{4}{*}[9,16]{} \\
\hline \multirow[t]{3}{*}{$\left(\mathrm{Zn}^{++}\right.$-dependent $)$} & HDAC5 & Nuc/Cyt & & SAHA & \\
\hline & HDAC7 & Nuc/Cyt & & \multirow{2}{*}{ Valproic acid } & \\
\hline & HDAC9 & Nuc/Cyt & & & \\
\hline Class IIb & HDAC6 & Mainly Cyt & Tubacin & TSA & [16] \\
\hline$\left(\mathrm{Zn}^{++}\right.$-dependent $)$ & HDAC10 & Mainly Cyt & & SAHA & {$[10]$} \\
\hline Class III & SIRT1 & Nuc/Cyt & Suramin & \multirow{7}{*}{ Nicotinamide } & \multirow{7}{*}[9,17]{} \\
\hline \multirow[t]{6}{*}{$\left(\mathrm{NAD}^{+}\right.$-dependent $)$} & SIRT2 & Nuc/Cyt & Suramin, AGK2 & & \\
\hline & SIRT3 & Nuc/Mitoch* & & & \\
\hline & SIRT4 & Mitochondria & & & \\
\hline & SIRT5 & Mitochondria & Suramin & & \\
\hline & SIRT6 & Nucleus & & & \\
\hline & SIRT7 & Nucleus & & & \\
\hline $\begin{array}{l}\text { Class IV } \\
\left(\mathrm{Zn}^{++} \text {-dependent }\right)\end{array}$ & HDAC11 & Nuc/Cyt & & $\begin{array}{l}\text { TSA } \\
\text { SAHA }\end{array}$ & {$[16]$} \\
\hline
\end{tabular}

life span [23, 43-45]. Our group has reported that administration of HDACIs protects organs and cells from lethal hemorrhagic shock-induced injury [36, 42, 46, 47]. Several converging lines of inquiry suggest that the protective mechanism of HDACIs may result from the fact that alter the response to ischemic injury and reduce damage in the important organs during the progress of hemorrhagic shock.

In the heart, ischemia induces histone deacetylase activity via deacetylation of histones $\mathrm{H} 3 / 4$ in vitro and in vivo [48]. Using standard murine model of heart ischemia-reperfusion, Granger. demonstrated that HDACI significantly reduce infarct area, even when delivered $1 \mathrm{~h}$ after the ischemic insult. HDACI decrease the response to ischemic injury and lessen the size of myocardial infarction [48]. In part, this is through prevention of ischemia-induced activation of gene programs that include hypoxia inducible factor- $1 \alpha$, cell death, and by decreasing vascular permeability in vivo and in vitro, which reduces vascular leak and myocardial injury.

In the liver, low oxygen increases HDAC1, 4, and 5 protein levels by 2 -fold and decreases acetylated histone H3 levels to $50 \%-75 \%$ of the control values in a turtle model of anoxia [49]. In a rat model of hemorrhagic shock, Gonzales reported that hemorrhage increased serum levels of lactate, lactate dehydrogenase, aspartate aminotransferase, and alanine aminotransferase. Alternatively, treatment with VPA (an HDACI) induced acetylation of histones (H2A, H3, and $\mathrm{H} 4$ ), and alleviated serum levels of these enzymes and prolonged survival (fivefold). Furthermore, hyperacetylation of the histone proteins indicated the presence of active genes and correlated with improved survival [50]. Gene expression profiling data from our group, in comparison to HS without treatment, has shown that VPA treatment upregulates expression of 17 genes at the early stage of HS, compared to HS without treatment (Fukudome et al., unpublished data). Two of these genes are peroxisome proliferator-activated receptor $\gamma$ coactivator- $1 \alpha$ (PGC- $1 \alpha)$ and dual specificity protein phosphatase 5 (DUSP5). PGC- $1 \alpha$ protects cells from oxidative stress by increasing expression of various antioxidant defense enzymes including superoxide dismutase and glutathione peroxidase [51]. DUSP5 is an inducible, nuclear, dual-specificity phosphatase, which specifically interacts with and inactivates the extracellular signal-regulated kinase (ERK) 1/2 MAP kinases in mammalian cells [52]. Inactivation of ERK1/2 MAP kinases by DUSP5 may be one of the mechanisms responsible for the protective properties of VPA in HS.

In the kidney, it has been discovered that ischemia/reperfusion induces a transient decrease in histone acetylation in proximal tubular cells. This is likely a result of a decrease in histone acetyltransferase activity as suggested by experiments with energy-depleted renal epithelial cells in culture [53]. During recovery after transient energy depletion in epithelial cells, the HDAC isozyme HDAC5 is selectively downregulated in parallel with the return of acetylated histone. Knockdown of HDAC5 by RNAi significantly increased histone acetylation and bone morphogenetic protein-7 (BMP7) expression [53]. In a rat model of HS, it was found that treatment of animal with VPA or SAHA markedly increases phosphorylation of Akt and decreases the expression of proapoptotic BAD (Bcl-xl/Bcl-2 associated death promoter) 
protein in kidney tissue [54]. Further investigation is needed to find if there is any relationship between HDAC5 inhibition and Akt activation.

In the brain, Faraco found that in the ischemic brain (subjected to $6 \mathrm{~h}$ of middle cerebral artery occlusion), histone $\mathrm{H} 3$ acetylation levels are dramatically decreased without evidence of a concomitant change in histone acetyltransferase or deacetylase activities. Treatment with SAHA ( $50 \mathrm{mg} / \mathrm{kg}$ i.p.) increased histone $\mathrm{H} 3$ acetylation within the normal brain (of approximately 8 -fold after $6 \mathrm{~h}$ ) and prevented histone deacetylation in the ischemic brain. These effects were accompanied by increased expression of the neuroprotective proteins heat-shock protein 70 (Hsp70) and B-cell lymphoma 2 (Bcl-2) in both control and ischemic brain tissue $24 \mathrm{~h}$ after the insult. At the same time point, mice injected with SAHA at 25 and $50 \mathrm{mg} / \mathrm{kg}$ had smaller infarct volumes compared with vehicle-receiving animals $(28.5 \%$ and $29.8 \%$ reduction, $P<.05$ versus vehicle). Recently, $\mathrm{Li}$ reported that VPA treatment induces acetylation of histone $\mathrm{H} 3$, increases expression of $\beta$-catenin and $\mathrm{Bcl}-2$ proteins, and prevents neuronal apoptosis in in vitro hypoxic condition $\left(0.5 \% \mathrm{O}_{2}\right)$ as well as in the in vivo model of $\mathrm{HS}$ [42]. These findings demonstrate that pharmacological inhibition of HDAC promotes expression of neuroprotective proteins within the ischemic brain and underscores the therapeutic potential of molecules inhibiting HDAC for HS-induced brain injury.

\subsection{Effect of HDACIs on Phosphoinositide 3-Kinase (PI3K)-} $A k t / P K B$ Pathway. Activation of PI3K enhances cell survival and antagonizes apoptosis via Akt/PKB activity in many cell types including cardiomyocytes, cardiac fibroblast, vascular smooth muscle cells (VSMCs), endothelial cells and hepatocytes $[41,55,56]$. Alam recently found that VPA exerts antiapoptotic effect through the Akt/PKB signaling pathway and improves survival in a swine model of traumatic hemorrhagic shock [41]. In this in vivo study, they compared cell protective effects of the HDAC inhibitor (VPA) with resuscitation using fresh whole blood (FWB) and a normal saline control. VPA treatment increased the levels of activated Akt, deactivated glycogen synthase kinase- $3 \beta$ (GSK-3 $\beta$ ), $\beta$ catenin, and Bcl-2 significantly when compared to FWB and saline control groups. However, the total Akt and total GSK$3 \beta$ levels did not differ across the three treatments [41]. VPA has been reported to directly and indirectly inhibit GSK$3 \beta$ [57]. However, it is not clear how the HDACI influences the Akt signaling in an animal model of trauma and hemorrhagic shock. There are several other possibilities for this pathway activation in addition to direct inhibition of GSK-3 $\beta$ (Figure 1).

2.2.1. An Increase of Acetylated Tribbles (TRB) 3 and Phosphatase and Tensin Homolog (PTEN) May Be Associated with PI3K/Akt Activity [58]. Growth factors such as insulin, insulin-like growth factor 1 (IGF-1), erythropoietin, and cytokines that reduce apoptosis rely almost exclusively on the PI3K/Akt pathway whereas GPCR-induced PI3K/Akt activation and cardioprotection occurs in response to several peptide agonists, including urocortin, ghrelin, and adrenomedullin as well as beta2-adrenergic receptor $\left(\beta_{2}\right.$ AR) stimulation $[55,59-61]$. In the heart, overexpression of Akt/PKB causes resistance to apoptosis [55]; knockout of Akt $2 / \mathrm{PKB} \beta$ enhances apoptosis in response to myocardial ischemia [62]. Consistent with a critical role for Akt/PKB in cell survival, loss or gain of TRB3 and PTEN activity leads to reduced or enhanced apoptosis, respectively $[63,64]$. Alternatively, increased expression of TRB3 and PTEN promotes apoptosis in cardiac myocytes $[63,65]$. PTEN is a dual protein/lipid phosphatase whose main substrate is phosphatidylinositol 3,4,5-triphosphate (PIP3), the product of PI3K. PTEN degrades PIP3 to an inactive form phosphatidylinositol 4,5-bisphosphate (PIP2) [55, 66-68], inhibiting Akt activation. PTEN is constitutively active and is the major downregulator of PI3K/Akt [69]. PTEN also forms signaling complexes with PDZ domaincontaining adaptors, such as the MAGUK (membraneassociated guanylate kinase) proteins. These interactions appear to be necessary for the metabolism of localized pools of PIP3 involved in regulating actin cytoskeleton dynamics. Acetylation is a major mechanism that regulates PTEN activity [70]. Histone acetylase p300/CREB-binding proteinassociated factor (PCAF) interacts with PTEN and acetylates lysines 125 and 128 which are located within the catalytic cleft of PTEN and are essential for PIP3 specificity. PCAF functions as a negative regulator of PTEN [71]. TRB3 is an intracellular pseudokinase that modulates the activity of several signal transduction cascades. TRB3 has been reported to inhibit the activity of Akt protein kinases [72]. TRB3 gene expression is highly regulated in many cell types, and hypoxia or endoplasmic reticulum (ER) stress promotes TRB3 expression. TRB3 binds to inactive and unphosphorylated Akt, thus preventing its phosphorylation [73]. It remains unknown whether and how PCAF regulates TRB3. Recently, Yao and Nyomba reported that acetylation status of TRB3 and PTEN is decreased in association with increased HDAC and decreased HAT activities. The hypoacetylated TRB3 and PTEN can inhibit the Akt-activity in a rat model of prenatal alcohol exposure [58], which suggests that HDACI treatment could inhibit the activity of TRB3 and PTEN, and therefore enhance Akt signaling.

\subsubsection{Induction of Hsp70 by HDACIs May Be Associated with} the PI3K/Akt Pathway. In a rat model of hemorrhagic shock, Gonzales found that VPA treatment increased the acetylation of nonhistone and histone proteins and expression of Hsp70 in rat myocardium, and significantly prolonged survival (5 fold) compared to the nontreatment control [4]. In rat cortical neurons, VPA treatment markedly upregulated Hsp70 protein levels, and this was accompanied by increased Hsp70 mRNA levels and promoter hyperacetylation and activity [74]. Other HDAC inhibitors-sodium butyrate, trichostatin A, and Class I HDAC-specific inhibitors MS-275 and apicidin — all possess the ability to induce HSP70.

Hsp70 is a molecular chaperone, cell-protective, and anti-inflammatory agent. Marinova recently reported that HDACIs increase Sp1 acetylation, and promote the association of Sp1 with the histone acetyltransferases p300 and recruitment of p300 to the Hsp70 promoter. Furthermore, 


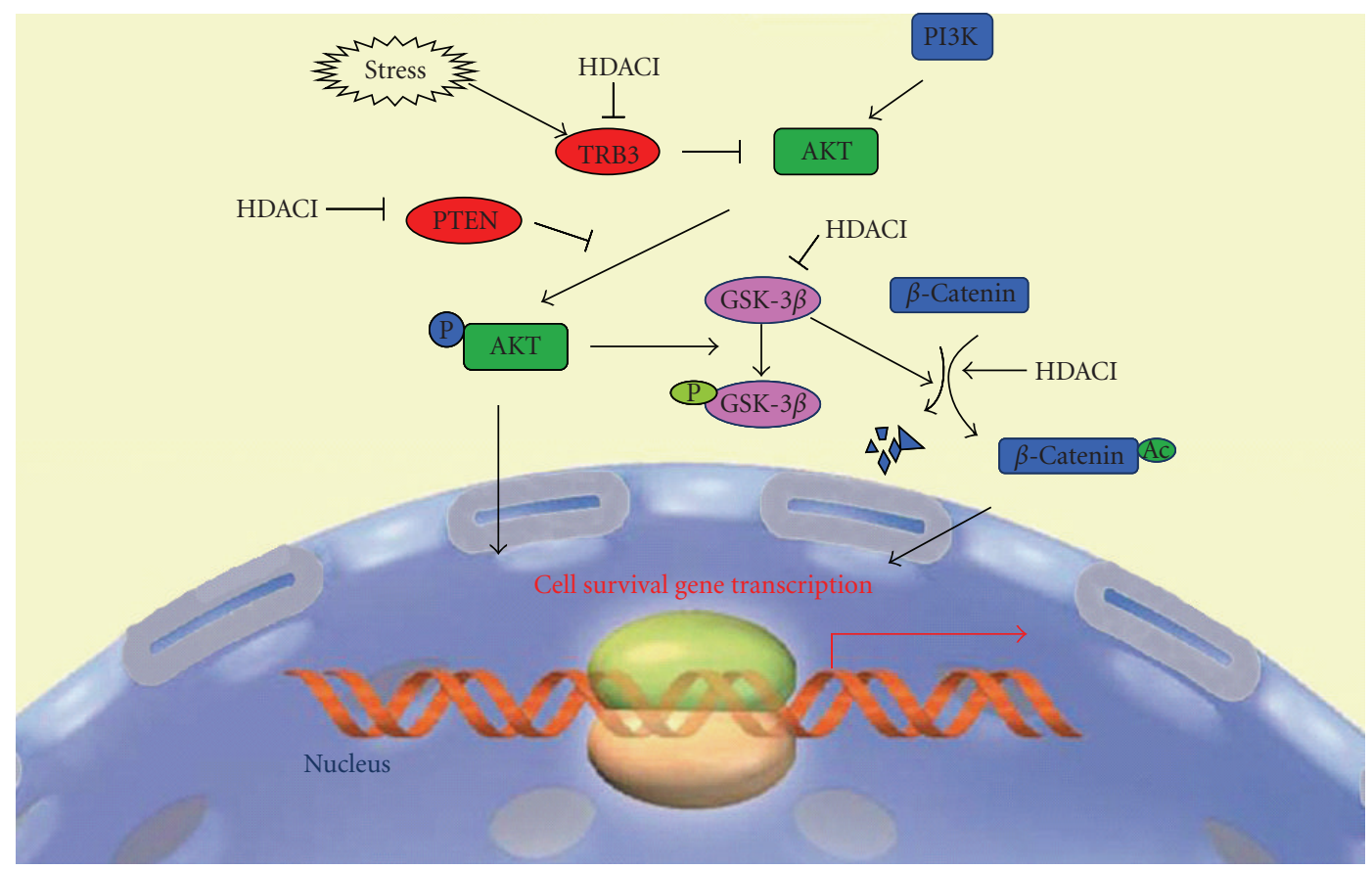

FIGURE 1: Effect of HDACIs on cell survival in hemorrhagic shock. HDACIs induce phosphorylation of AKT by inhibition of TRB3 and PTEN. While AKT stimulates transcription of cell survival genes through several other pathways, phosphorylated AKT also phosphorylates GSK-3 $\beta$. Phosphorylated GSK-3 $\beta$ becomes inactivated form, which cannot degrade $\beta$-catenin. HDACIs (e.g., VPA) can also directly inhibit GSK-3 $\beta$. Moreover, HDACIs induce acetylation and nuclear translocation of $\beta$-catenin, leading to downstream survival gene transcription. P, phosphorylation; Ac, acetylation.

HDACI-induced cell protection can be prevented by blocking Hsp70 induction [74]. In addition, Gao and Newton showed that Hsp70 directly binds and stabilizes Akt/PKB as well as protein kinase $\mathrm{A}$ and protein kinase $\mathrm{C}$, thus prolonging the signaling lifetime of the kinases [75]. Taken together, these findings suggest that the PI3K/Akt pathway and Sp1 are likely involved in Hsp70 induction by HDACIs, and this induction may in turn interact with Akt/PKB to sustain the active state of Akt to protect the cells from apoptosis.

In addition to the interaction with the Akt/PKB pathway, Hsp70 also directly interacts with different proteins of the tightly regulated programmed cell death machinery, thereby blocking the apoptotic process at distinct key points. For example, Hsp70 can inhibit the apoptotic cascade [76, 77], decrease formation of the functional apoptosome complex $[78,79]$, prevent late cascade-dependent events such as activation of cytosolic phospholipase A2 and changes in nuclear morphology, and protect cells from forced expression of caspase-3 [80]. Moreover, Hsp70 inhibits c-Jun Nterminal kinase (JNK)-mediated cell death by suppressing JNK phosphorylation either directly and/or through the upstream SEK kinase [81-83], and hampers TNF-mediated apoptosis by inhibition of ASK-1 [84].

It has been noted that Hsp70 has different functions depending on its intracellular or extracellular location. Intracellular $\mathrm{Hsp} 70$ has a protective function which allows the cells to survive lethal conditions [85]. Extracellularly located or membrane-bound Hsp70 mediates immunological functions. They can elicit an immune response and will be discussed later.

\subsection{Effect of HDACIs on Gut and Lung in Hemorrhagic} Shock. Hemorrhagic shock is characterized by insufficient tissue perfusion which is needed to meet the oxygen and nutrient demands of cells. The host response to hemorrhagic shock involves a coordinated expression of mediators that act both locally and systemically with profound effects on organ function. The accumulated evidences suggest that gut and lung, especially gut, represent important site(s) of immune mediator production and inflammation. Although two major hypotheses, gut-lymph-lung axis [86, 87] and gut-liver-lung axis $[88,89]$, have brought much debate based on the different findings, it is clear that hemorrhagic shock is associated with intestinal ischemia which makes gut a proinflammatory organ. For the fact that most of these mediators are produced by cells of the immune system, significant immunoregulatory actions occur within the gutliver and/or lymph-lung axis and in peripheral immune sites (Figure 2). It is well established that the gut plays a pivotal pathogenic role in the pathogenesis of SIRS and multiorgan dysfunction syndrome (MODS) [90, 91].

It is clear that gut ischemia can cause lung injury, but how can it be prevented? We proposed that HDACIs could protect lung from gut-originated damage. To test this 


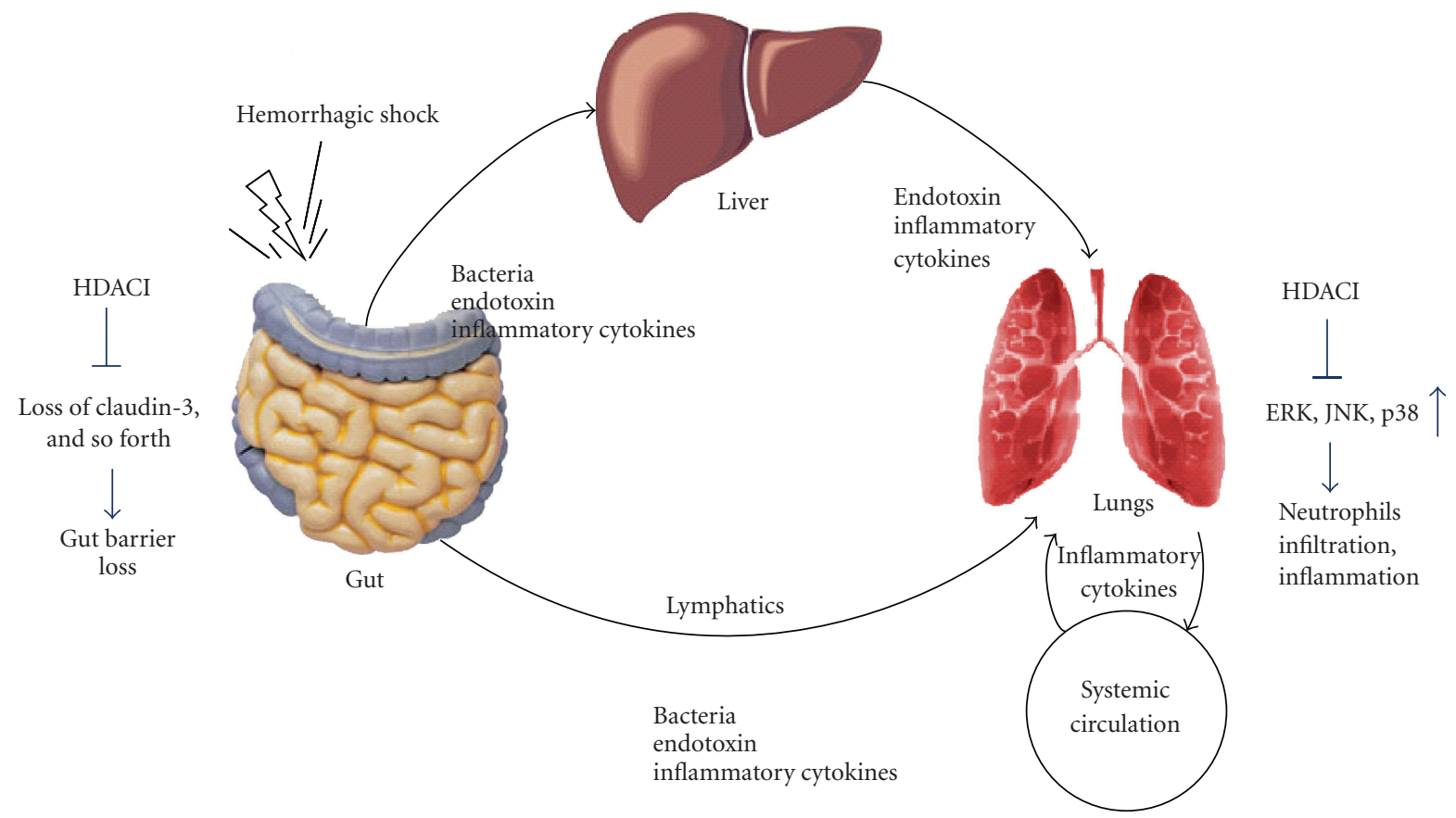

FIgURE 2: Effect of HDACIs on gut-liver/lymph-lung axis in response to hemorrhagic shock. Hemorrhagic shock causes destruction of the gut barrier due to tight junction protein (e.g., claudin-3) loss. Bacteria, endotoxin, and inflammatory cytokines enter into circulation and lung. In the lung tissue, MAPKs are stimulated and neutrophils infiltrated, resulting in acute lung injury. HDACIs block these processing by inhibition of tight junction protein loss in gut and inactivation of MAPKs in lung.

proposal, the superior mesenteric artery (SMA) of rats was clamped for 60 min to induce ischemia and then released for reperfusion. Without any treatment, gut ischemia induced production of proinflammatory cytokines or prostaglandinlike compound such as IL-6, cytokine-induced neutrophil chemoattractant (CINC), 8-isoprostane in lung tissues, and increased neutrophil lung infiltration. However, treatment with VPA significantly reduced these mediators in lung tissues and improved survival in a rat model of ischemia and reperfusion (Kim, unpublished data). It is not clear how VPA protects gut from ischemic damage and prevents acute lung injury. However, based on our recent findings, it is conceivable that VPA maintains gut barrier in part through stabilizing intestinal tight junctions (TJ) (Figure 2).

The function of gut barrier is based on intestinal tight junctions. Encircling epithelial cells, the intestinal TJ is a region where the plasma membrane of epithelial cells forms a series of contacts that appear to completely occlude the extracellular space and create an intercellular barrier and intramembrane diffusion fence [92]. Normally, TJ is anchored in the cell via TJ proteins and filamentous actin (Factin) cytoskeleton. Hypoperfusion, or ischemia, can cause disruption of F-actin cytoskeleton with subsequent TJ loss and barrier failure. Bacterial translocation to mesenteric lymph nodes, liver, and spleen is found at a very early stage of hemorrhagic shock [89]. Loss of gut wall integrity not only leads to paracellular leakage of microbial products $[93,94]$ but also contributes to the development of systemic inflammation and distant organ failure [95].
One of the major TJ proteins is claudin-3. Although the exact function of claudin-3 within TJ is not completely clear, it appears to be important in TJ formation and function [96]. Recent studies from our group [97] and others [89] have shown that HS leads to destruction of the gut barrier due to TJ protein loss. Also, it was found that the claudin-3 protein is released into circulation very early $(30-60 \mathrm{~min})$ after the onset of HS [97]. Alternatively, CINC, a chemokine that promotes neutrophil chemotaxis, is significantly elevated in serum and lung tissue with increased myeloperoxidase (MPO) levels at $4 \mathrm{~h}$ after hemorrhage. However, VPA treatment reverses HS-induced claudin-3 loss from the intestine and reduces the levels of CINC and MPO in serum and lung significantly (Fukudome, unpublished data). These findings suggest that VPA can stabilize claudin-3 in gut TJ, maintain the intestinal barrier, and prevent harmful gutderived substances from getting into the systemic circulation.

Furthermore, we recently demonstrated that sublethal hemorrhagic shock (40\% blood loss) results in phosphorylation (activation) of ERK, JNK and p38 mitogen-activated protein kinase (MAPK) in lung tissues at 1 and 4 hours compared to the sham group. Postshock administration of VPA (300 mg/kg, iv) significantly attenuates the MAPK activation but does not affect expression of total ERK, JNK and p38 proteins [98]. These kinases are globally expressed and known to be key regulators of stress-mediated cell fate decision. Activation of these proteins has been strongly associated with poor outcomes while inhibition of MAP kinases has been associated with survival in hemorrhage models [98]. 
VPA can also directly modulate MAPK activation. Cao has studied the effects of HDACI treatment on LPSinduced activation of p38 MAPK and found that HDACIs inhibit p38 phosphorylation. In this experiments, HDACIs induce acetylation of MAP kinase phosphatase-1 (MKP-1), a protein that dephoaphorylates MAPK and inactivates MAPK pathways. These results demonstrated that HDACI treatment and MKP-1 acetylation increases the interaction between MKP-1 and p38 MAPK, and results in p38 inactivation, reduced inflammation and increased survival among LPS-exposed mice [34]. Whether similar acetylationmediated mechanisms exist for the regulation of ERK and JNK is still unknown but is highly plausible.

\section{HDACIs in Septic Shock}

The progression of infection to septic shock begins with the release of inflammatory mediators at the local site of microbe invasion. This induces the migration of white blood cells and platelets to the infection site and contributes to endothelial damage and increased microvascular permeability. Blood flow is also reduced which sets the stage for ischemiareperfusion injury. These physiologic processes are part of the exaggerated SIRS, which can lead to MODS.

Many of the body's reactions to infection with gramnegative organisms are due to lipopolysaccharide (LPS), a component of the outer bacterial cell wall membrane, also referred to as endotoxin. It can induce septic shock physiology and has been used extensively to produce shock in laboratory models. LPS exerts the downstream signals through the Toll-like Receptor-4 (TLR4). TLR4 activates two downstream pathways: Myeloid differentiation factor 88 (MyD88)-dependent and MyD88-independent pathways. The former leads to the production of proinflammatory cytokines such as IL- 6 , TNF- $\alpha$, and IL- 12 with the quick activation of nuclear factor-kappaB (NF- $\kappa \mathrm{B})$ and MAPK. The MyD88-independent pathway is associated with activation of interferon (IFN) regulatory factor 3 (IRF3), subsequent induction of IFN- $\beta$, and maturation of dendritic cells.

It has been shown that HDACIs exert anti-inflammatory activities via the suppression of inflammatory cytokines and nitric oxide [99]. In LPS-stimulated human peripheral blood mononuclear cells, HDACI (ITF2357) reduces the release of TNF- $\alpha$, IL- $1 \beta$, and IFN- $\gamma$ [100]. Other HDACIs such as TSA and SAHA have been shown to decrease LPS-induced inflammation in mice $[5,34,101]$. In RAW 264.7 cells, treatment of the macrophages with SAHA significantly suppresses LPSinduced gene expression and protein production of IL- $1 \beta$, IL- 6 , and TNF- $\alpha[5,101]$. In an in vivo rodent model of septic shock, HDACIs attenuate acute lung and liver injury and improve survival $[35,101,102]$. Further mechanistic studies have demonstrated that HDACIs play an important inhibitory role in TLR-4-MyD88 signaling pathways via NF$\kappa \mathrm{B}$ and MAPKs. Protein acetylation provides a key for the control of inflammatory response (Figure 3 ).

3.1. HDACIs Affect NF- $\kappa B$ Activity. NF- $\kappa \mathrm{B}$ is an ubiquitously expressed transcription factor that plays an important role in innate immunity and other critical processes. The NF$\kappa \mathrm{B}$ family consists of p50, p52, p65 (Rel A), c-Rel, and Rel B, which form homo- or hetero-dimers. The p50/p65 heterodimer is the most frequently found combination in mammals. Inactive NF- $\kappa \mathrm{B}$ complexes are retained in the cytoplasm by the $\mathrm{I} \kappa \mathrm{B}$ inhibitor. In innate immune signaling, host cells can respond to the threat of bacterial pathogens (e.g., LPS) via extracellular receptor TLRs (e.g., TLR4). TLR4 interacts with MyD88 and recruits interleukin-1 receptorassociated kinase 1 (IRAK1) and IRAK4 to the receptor complex. IRAK1 phosphorylates TNF receptor-associated factor 6 (TRAF6) leading to the activation of the $\mathrm{I} \kappa \mathrm{B}$ kinase (IKK). The activation of IKK results in I $\kappa$ B phosphorylation, triggering its ubiquitination and proteasomal degradation. Free NF- $\kappa \mathrm{B}$ then translocates to the nucleus to regulate the transcription of chemokines, cytokines, and other inflammatory response molecules [103].

In the nucleus, $\mathrm{p} 50$ and $\mathrm{p} 60$ can be regulated by acetylation. The function of acetylated NF- $\kappa \mathrm{B}$ is complicated. Acetylation of p50 at K431, K440, and K441 promotes higher DNA-binding affinity towards NF- $\kappa \mathrm{B}$ target sequences correlating with increased p300 (histone acetyltransferase) recruitment and transcriptional activation $[104,105]$. The p300 can acetylate p65 at multiple lysine residues and result in different consequence. Acetylation of p65 at K221 and $\mathrm{K} 310$ is associated with an increased transcription of NF- $\kappa \mathrm{B}$ target genes [106] and is required for the full activity of p65 [107]. In contrast, HDAC 1 and HDAC3 deacetylate p65 at either K221 or K310, resulting in the inhibition of NF- $\kappa$ B. Additionally, K122 and K123 acetylation reduces p65 DNAbinding affinity accompanied with increased $\mathrm{I} \kappa \mathrm{B}$ interaction and nuclear export [108]. The p300-mediated acetylation of K314 and K315 in p65 has no obvious effect on NF- $\kappa$ B DNA binding or translocation.

Indeed, HDACIs have been shown to induce hyperacetylation and repress NF- $\kappa \mathrm{B}$ signaling and expression of several target genes [109-111]. Conversely, other groups reported that HDACIs enhance NF- $\kappa \mathrm{B}$-dependent gene expression but were in the presence of TNF $\alpha$ [112-115]. Presumably, inhibitory or enhancive effects of HDACIs on NF- $\kappa$ B rely on the cell type, expression of a different set of HDAC isoforms, acetylation/deacetylation of NF- $\kappa \mathrm{B}$ at different lysine or by different enzyme, as well as the source of cell stimulation (e.g., LPS, cytokines and high glucose levels) [99].

3.2. HDACIs Inhibit MAPK Activity. In mammalian cells, JNK and p38 MAPKs activate mitogen and stress-activated protein kinase 1 (MSK1) such as ribosomal S6 kinase 2 (RSK2). RSK2 has a strong activity towards phosphorylation of histone $\mathrm{H} 3$ at Ser10 [116]. The phosphorylation of histone $\mathrm{H} 3$ occurs on the promoters of the subset on the stimulusinduced cytokine and chemokine genes, recruits NF- $\kappa \mathrm{B}$ to the promoters, and stimulates transcription of inflammatory genes such as IL-6, IL-8, IL-12, and macrophage chemoattractant protein 1 (MCP-1) [117].

It has been reported that HDAC inhibitor TSA enhances the activity of mitogen-activated protein kinase phosphotase-1 (MKP-1) [34, 118]. MKP-1 is a nuclear-localized dualspecificity phosphatase and preferentially dephosphorylates 


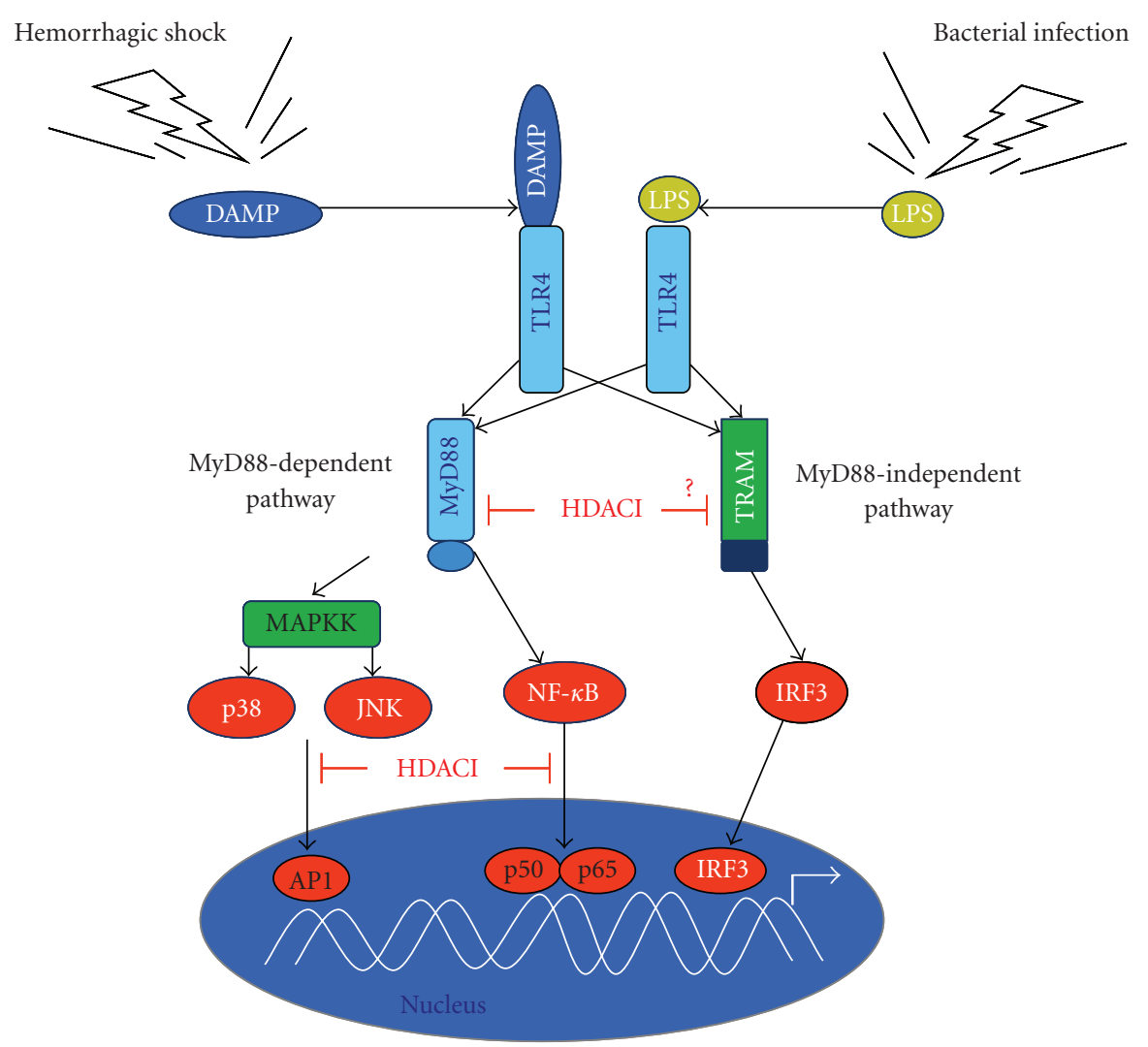

FIGURE 3: TLR4 signaling - a converged immune response pathway for hemorrhagic shock and septic shock. TLR4 not only serves as a key sensor of pathogen-associated molecular patterns (PAMPs) but also is proposed recently to act as a receptor for some endogenous molecules called "alarmins". HDACIs block TLR4 signaling at multiple steps; therefore, they can inhibit immune response for both hemorrhagic shock and septic shock.

MAPKs such as p38 and JNK. Recently, Cao showed that MKP-1 interacts with HAT and that acetylation of MKP-1 inhibits TLR4 signaling [34]. They immunoprecipitated the histone acetylase p 300 and showed that it was associated with MKP-1. Moreover, MKP-1 was acetylated by p300 on lysine residue $\mathrm{K} 57$ within its substrate-binding domain. Acetylation of MKP-1 induced by TSA enhanced the interaction between MKP-1 and p38 MAPK, suggesting that HDACI could increase the phosphatase activity and inactivate p38 MAPK. Indeed, TSA increased MKP-1 acetylation and blocked MAPK signaling in wild-type (WT) cells. However, TSA had no effect in cells lacking MKP-1. Furthermore, TSA reduced inflammation and mortality in WT mice treated with LPS, but failed to protect MKP-1 knockout mice. These findings suggest that acetylation of MKP-1 inhibits innate immune signaling, and targeting the MAPK pathway by HDACI may be an important approach in the treatment of septic shock.

Recently, our group has found that HDAC inhibitor SAHA can reduce the expression of MyD88 gene and protein in vitro and in vivo after LPS insult [101]. Moreover, SAHA acetylates heat shock protein 90 (Hsp90) and deassociates the protein from IRAK1, resulting in IRAK1 degradation (Chong, unpublished data). Our new findings have provided evidence that inhibition of HDAC can block, at least in part, activity of NF- $\kappa$ B and MAPKs in the initial steps of the TLR4MyD88- NF- $\kappa$ B/MAPK pathway (Figure 3).

3.3. TLR4 Signaling - a Converged Immune Response Pathway for Hemorrhage and Sepsis. Hemorrhage and sepsis activate several inflammatory and innate immune signaling pathways [119]. Systemically, these pathways promote recruitment of neutrophils and release of inflammatory cytokines [120]. Within the cells, the inflammatory stimuli induce MAPKdependent phosphorylation or phosphoacetylation of histone proteins and modulate the epigenetic accessibility of DNA in the cell [117]. Downstream, these signals change the gene expression profile of the cells insulted with hemorrhage or sepsis, altering the competing signals (e.g. prosurvival and prodeath, or anti-inflammation and proinflammation), that ultimately determine their fate. Two key pathways in hemorrhage- and sepsis-induced cellular injuries are the mitogen activated protein (MAP) kinase and NF- $\kappa \mathrm{B}$ pathways. These proteins, ERK1/2, JNK, p38 protein kinase, and NF- $\kappa \mathrm{B}$, are globally expressed and known to be key regulators of cell fate decisions $[121,122]$, which are involved in TLR4 signaling pathway.

It is well known that mammalian TLR4 serves as a key sensor of pathogen-associated molecular patterns (PAMPs) 
such as LPS. More recently, an additional role for TLR4 has been proposed. A number of reports have emerged to suggest that diverse molecules of host-cell origin may also serve as endogenous ligands of TLR4 $[2,123,124]$. These molecules represent members of a recently identified family of molecules, including Hsp70, fibrinogen, high-mobility group box 1 (HMGB1), nucleolin, and annexins [123]. They have been found to serve as mediators of inflammation that may be expressed or released in response to tissue damage from trauma including HS. These molecules have been described as "alarmins", which are the equivalent of PAMPs but are endogenous molecules. They are rapidly released following nonprogrammed cell death but are not delivered by apoptotic cells. Immune cells can also be induced to produce and release alarmins without dying. Generally, this is done by using specialized secretion systems or by the endoplasmic reticulum (ER)-Golgi secretion pathway. Endogenous alarmins and exogenous PAMPs can be considered subgroups of a larger family of damage-associated molecular patterns (DAMPs). They convey a similar message and elicit similar responses through TLR4 (Figure 3) leading to activation of MAPKs and NF- $\kappa$ B pathways $[123,125]$.

HDACIs have been described above for their prosurvival and anti-inflammatory properties. The combined prosurvival and anti-inflammatory effectiveness makes them a highly attractive choice for the treatment of lethal hemorrhagic shock and its septic complications. In our preliminary studies, we have already discovered that HDACIs not only inhibit expression of proinflammatory cytokines and chemokines in cells but also prevent some alarmins from being released from cells in hemorrhagic shock and septic shock ( $\mathrm{Li}$, unpublished data). Further investigation with different models (e.g., "two-hit" model) are being planned to further clarify the precise mechanisms of action and the role played by protein acetylation.

\section{Contradiction and Explanation}

Although most studies have demonstrated that HDACIs induce expression of prosurvival/anti-inflammatory genes and proteins, some authors have reported different results [126]. Wetzel et al. found that TSA causes inhibition of glioma cell growth by both cell cycle arrest and apoptosis [127], which contradicts the study of Avila et al. that TSA increases neurons survival [31]. Aung et al. observed that treatment of bone marrow-derived macrophages with TSA enhances LPS-induced expression of proinflammatory genes [128], which disagrees to the finding of Han and Lee that TSA significantly decreases mRNA and protein levels of the proinflammatory cytokines in macrophages [129]. This discrepancy of pro/anti-apoptosis and pro/antiinflammation may be due to differences in cell types, HDAC isoform, acetylation/deacetylation of a protein by different enzymes or at different lysine residues, and variances in the type of cellular stimulation, and so forth [99].

For instance, HDACIs have been shown to potentiate TNF- $\alpha$ expression in microglial cells [130] but to suppress TNF- $\alpha$ expression in cultured human peripheral blood mononuclear cells and macrophages in response to LPS $[5,131]$.
It is not clear how HDACIs function differently in these different cell types. However, there are numerous reasons for the differential effects of HDACIs between normal and transformed cells. HDACIs induce different phenotypes in various transformed cells, including growth arrest, activation of the extrinsic and/or intrinsic apoptotic pathways, autophagic cell death, reactive oxygen species (ROS)-induced cell death, mitotic cell death, and senescence. In comparison, normal cells are relatively more resistant to HDACI-induced cell death $[132,133]$. In many transformed cells, ROS-oxidationreduction pathways are important mechanisms of HDACIinduced transformed cell death [134]. Thioredoxin (Trx) acts as a hydrogen donor required for the activation of many proteins, including ribonucleotide reductase which is essential for DNA synthesis and transcription factors and is an antioxidation scavenger of ROS [135]. HDACIs upregulate the expression of Trx-binding protein 2 (TBP2) [136], which binds and inhibits Trx activity, and can cause downregulation of Trx in transformed but not normal cells [134, 136]. Trx is an inhibitor of apoptosis signal regulating kinase 1 (ASK1) [137]. Therefore, inhibition of Trx by HDACIs in transformed cells subsequently results in cell apoptosis.

Differential cellular expression of HDACs is another factor that causes the discrepancy. The HDACs have been found to interact with different proteins and transcription factors. HDAC1 interacts with retinoblastoma protein [138] and SP1 [139]. HDAC2 interacts with NF- $\kappa B$ [140]. HDAC1 and HDAC2 also interact directly with DNA topoisomerase II to modify topoisomerase activity [141]. HDAC3 interacts with NF- $\kappa$ B [142]. HDAC4 and HDAC5 interact with myocyte enhancer factor 2 (MEF2) [143]. Due to the proteinprotein interaction, inhibition of HDAC with different HDAC inhibitor results in different outcome. In cultured neonatal mouse cardiomyocytes, Zhu et al. have shown that LPS insult increases HDAC 3 activity and suppresses TNF- $\alpha$ expression. The upregulation of HDAC3 activity was abrogated by a pan-HDAC inhibitor TSA and class I HDAC inhibitor apicidin, but not by class II HDAC inhibitors [142].

Posttranslational modifications of a protein by different enzymes or at different amino acid residues can cause different results. For instance, phosphorylation of NF- $\kappa-B$ p 65 preferentially interacts with $\mathrm{p} 300 / \mathrm{CBP}$, an acetyltransferase, resulting in p65 acetylation at multiple sites. Acetylation of K221 and K310 is associated with an increased transcription of NF- $\kappa$ B target genes [106], while K122 and K123 acetylation reduces p65 DNA-binding affinity accompanied with increased $\mathrm{I} \kappa \mathrm{B}$ interaction and nuclear export [108]. Deacetylation of p65 K310 by SIRT1 inhibits transcription of NF- $\kappa \mathrm{B}$ target genes [144], and deacetylation of p65 at either $\mathrm{K} 221$ or K310 by HDAC1 and HDAC3 results in the inhibition of NF- $\kappa$ B [145].

In addition, a study from Wilson and colleagues suggests that the opposite effects of HDACIs may result from the effects of acetylation on specific combinatorial interactions required for efficient transcription of individual genes [146]. They used the mouse mammary tumor virus (MMTV) promoter to assess the consequences of inhibiting histone deacetylase activity on transcriptional activation mediated by the progesterone receptor in vivo. In human breast cancer 
cells, TSA induced global histone hyperacetylation, and this effect occurred independently of the presence of the hormone. Interestingly, chromatin immunoprecipitation analysis revealed no significant change in the level of acetylated histones associated with MMTV promoter following TSA treatment. In these cells, the MMTV promoter adopted a constitutively "open" chromatin structure. Treatment with TSA converted the MMTV promoter into a "closed" chromatin structure, evicted the transcription factor nuclear factor-1 from the promoter, and downregulated chromatin remodeling proteins and coregulatory molecules known to participate in the activation of the promoter-effects that occurred in the absence of histone acetylation of the local promoter chromatin structure.

The effects of HDACIs depend upon the "cell context" which in turn influences acetylation or the interaction of HDACs with histone and nonhistone proteins. Ideally, comprehensive consideration of cell type, activity of HDAC isoforms and the nature of cell stimulation should be taken into account when effects of the inhibitor are examined in an experimental model. Lack of attention to these details can create an erroneous impression of contradictory results.

\section{Future Perspectives}

Current therapies for massive hemorrhage and severe sepsis largely focus on restoring tissue perfusion through resuscitation but have failed to address the specific cellular dysfunction caused by shock. Acetylation is rapidly emerging as a key mechanism that regulates the expression of numerous genes (epigenetic modulation through activation of nuclear histone proteins), as well as functions of multiple nonhistone proteins involved in key cellular functions such as cell survival, repair/healing, and anti-inflammation. HDACIs hold great promise as a new class of agents for restoration of protein acetylation and treatment of hemorrhagic and septic shock.

Future studies should further elucidate the function of individual HDAC isoforms in severe hemorrhage and inflammation and assess potential effects of HDACIs on sepsis following hemorrhagic shock. Since individual HDAC isoforms have distinctive physiological functions, it is important to develop next generation of HDACIs. The new HDACIs could then target specific HDAC isoforms and presumably would result in improved efficacy relative to the first generation pan inhibitors such as SAHA and TSA but with little adverse effects. In addition to being used as prosurvival agents for severe trauma hemorrhage, HDACIs could be used as the combined prosurvival and anti-inflammatory drugs to prevent hosts from sepsis and even to treat sepsis following hemorrhage.

\section{Summary}

Experimental evidence has shown that treatment with HDACIs increases endurance of animals subjected to lethal blood loss. The survival benefit is seen even when the drugs are administered postinsult, and is reproducible in different species including large animal models of polytrauma.
Protective properties of HDACIs are not limited to hemorrhagic shock; HDACI treatment can also improve survival in LPS models of septic shock. Administration of HDACIs modulates the immune system to create a favorable phenotype not only during the acute phase of hemorrhagic shock but also later when the septic complications are likely to occur. Repeated successes of HDACIs in well-designed animal models of hemorrhagic shock (small and large animals) and septic shock (pre- and postshock treatments) suggest that modulation of protein acetylation is potentially a very useful strategy for the treatment of these critical diseases.

\section{Abbreviations}

ASK1: Apoptosis signal regulating kinase 1

BAD: $\quad$ Bcl-xl/Bcl-2 associated death promoter

Bcl-2: B-cell lymphoma 2

$\beta_{2}$-AR: Beta2-adrenergic receptor

BMP7: Bone morphogenetic protein 7

CBP: $\quad$ Cyclic AMP (cAMP) response element

CINC: Cytokine-induced neutrophil chemoattractant

DAMPs: Damage-associated molecular patterns

DNA: Deoxyribonucleic acid

DUSP5: Dual specificity protein phosphatase 5

ELISA: Enzyme-linked immunosorbent assay

ER: Endoplasmic reticulum

ERK: Extracellular signal regulated kinase

F-actin: Filamentous actin

FWB: $\quad$ Fresh whole blood

GSK-3 $\beta$ : Glycogen synthase kinase- $3 \beta$

$\mathrm{H}$ : Histone

HATs: Histone acetylases

HDA1: Histone deacetylase A1

HDACs: Histone deacetylases

HDACIs: Histone deacetylase inhibitors

HMGB1: High mobility group box 1

HS: Hemorrhagic shock

Hsp 70: Heat shock protein 70

Hsp 90: Heat shock protein 90

IFN: Interferon

IGF-1: Insulin-like growth factor 1

IKK: $\quad$ I $\kappa$ B kinase

IRAK 1: Interleukin-1 receptor associated kinase 1

IRF3: Interferon regulatory factor 3

IV: Intravenous (injection into a vein)

JNK: c-Jun N-terminal kinase

LPS: Lipopolysaccharide

MAGUK: Membrane-associated guanylate kinase

MAPK: Mitogen-activated protein kinase

MCP-1: Macrophage chemoattractant protein 1

MEF2: Myocyte enhancer factor 2

MKP-1: MAP kinase phosphatase 1

MMTV: Mouse mammary tumor virus

MODS: Multiorgan dysfunction syndrome

MPO: Myeloperoxidase

MSK1: Mitogen and stress-activated protein kinase 1

MyD88: Myeloid differentiation factor 88 
NAD: Nicrotinamide adenine dinucleotide

NF- $\kappa$ B: Nuclear factor kappa B

PAMPs: Pathogen-associated molecular patterns

PCAF: p300/CREB-binding protein-associated factor

p300: p300 histone acetyl transferase

PGC-1 $\alpha$ : Peroxisome proliferator-activated receptor $\gamma$ coactivator- $1 \alpha$

PI3K: $\quad$ Phosphoinositide 3 kinase

PIP2: $\quad$ Phosphatidylinositol 4,5-bisphosphate

PIP3: phosphatidylinositol 3,4,5-triphosphate

PKB: $\quad$ Protein kinase B

PTEN: Phosphatase and tensin homolog

ROS: Reactive oxygen species

RSK2: Ribosomal S6 kinase 2

SAHA: Suberoylanilide hydroxamic acid

SIRS: Systemic inflammatory response syndrome

SIRT: $\quad$ Sirtuins

SMA: $\quad$ Superior mesenteric artery

RT-PCR: Reverse transcription polymerase chain reaction

TBP2: $\quad$ Trx binding protein 2

TFs: $\quad$ Transcription factors

TJ: $\quad$ Tight junction

TLR4: Toll-like receptor 4

TNF- $\alpha$ : Tumor necrosis factor $\alpha$

TRAF6: TNF receptor associated factor 6

TRB3: Tribbles 3

Trx: $\quad$ Thioredoxin

TSA: Trichostatin A

VPA: Valproic acid

VSMCs: Vascular smooth muscle cells

WT: Wild type.

\section{Acknowledgments}

Dr. Alam acknowledges grant support from the National Institutes of Health (RO1 GM084127), Defense Advanced Research Projects Agency (W911NF-06-1-0220), Office of Naval Research (N000140910378), and the US Army Medical Research Material Command (GRANTT00521959).

\section{References}

[1] M. Keel and O. Trentz, "Pathophysiology of polytrauma," Injury, vol. 36, no. 6, pp. 691-709, 2005.

[2] K. P. Mollen, R. M. Levy, J. M. Prince et al., "Systemic inflammation and end organ damage following trauma involves functional TLR4 signaling in both bone marrowderived cells and parenchymal cells," Journal of Leukocyte Biology, vol. 83, no. 1, pp. 80-88, 2008.

[3] T. Lin, H. B. Alam, H. Chen et al., "Cardiac histones are substrates of histone deacetylase activity in hemorrhagic shock and resuscitation," Surgery, vol. 139, no. 3, pp. 365376, 2006.

[4] E. Gonzales, H. Chen, R. Munuve et al., "Valproic acid prevents hemorrhage-associated lethality and affects the acetylation pattern of cardiac histones," Shock, vol. 25, no. 4, pp. 395-401, 2006.
[5] Y. Li, B. Liu, H. Zhao et al., "Protective effect of suberoylanilide hydroxamic acid against lps-induced septic shock in rodents," Shock, vol. 32, no. 5, pp. 517-523, 2009.

[6] G. Vidali, E. L. Gershey, and V. G. Allfrey, "Chemical studies of histone acetylation. The distribution of epsilon$\mathrm{N}$-acetyllysine in calf thymus histones," Journal of Biological Chemistry, vol. 243, no. 24, pp. 6361-6366, 1968.

[7] P. A. Marks and M. Dokmanovic, "Histone deacetylase inhibitors: discovery and development as anticancer agents," Expert Opinion on Investigational Drugs, vol. 14, no. 12, pp. 1497-1511, 2005.

[8] N. Carey and N. B. La Thangue, "Histone deacetylase inhibitors: gathering pace," Current Opinion in Pharmacology, vol. 6, no. 4, pp. 369-375, 2006.

[9] D. M. Chuang, Y. Leng, Z. Marinova, H. J. Kim, and C. T. Chiu, "Multiple roles of HDAC inhibition in neurodegenerative conditions," Trends in Neurosciences, vol. 32, no. 11, pp. 591-601, 2009.

[10] T. Suzuki, "Explorative study on isoform-selective histone deacetylase inhibitors," Chemical and Pharmaceutical Bulletin, vol. 57, no. 9, pp. 897-906, 2009.

[11] S. Voelter-Mahlknecht, A. D. Ho, and U. Mahlknecht, "Chromosomal organization and localization of the novel class IV human histone deacetylase 11 gene," International Journal of Molecular Medicine, vol. 16, no. 4, pp. 589-598, 2005.

[12] A. J. M. De Ruijter, A. H. Van Gennip, H. N. Caron, S. Kemp, and A. B. P. Van Kuilenburg, "Histone deacetylases (HDACs): characterization of the classical HDAC family," Biochemical Journal, vol. 370, no. 3, pp. 737-749, 2003.

[13] E. Hu, E. Dul, C. M. Sung et al., "Identification of novel isoform-selective inhibitors within class I histone deacetylases," Journal of Pharmacology and Experimental Therapeutics, vol. 307, no. 2, pp. 720-728, 2003.

[14] F. Dangond and S. R. Gullans, "Differential expression of human histone deacetylase mRNAs in response to immune cell apoptosis induction by Trichostatin A and butyrate," Biochemical and Biophysical Research Communications, vol. 247, no. 3, pp. 833-837, 1998.

[15] A. Mai, S. Massa, R. Pezzi, D. Rotili, P. Loidl, and G. Brosch, "Discovery of (aryloxopropenyl)pyrrolyl hydroxyamides as selective inhibitors of class IIa histone deacetylase homologue HD1-A," Journal of Medicinal Chemistry, vol. 46, no. 23, pp. 4826-4829, 2003.

[16] A. A. Lane and B. A. Chabner, "Histone deacetylase inhibitors in cancer therapy," Journal of Clinical Oncology, vol. 27, no. 32, pp. 5459-5468, 2009.

[17] M. Gertz and C. Steegborn, "Function and regulation of the mitochondrial Sirtuin isoform Sirt5 in Mammalia," Biochimica et Biophysica Acta, vol. 1804, no. 8, pp. 1658-1665, 2010.

[18] S. J. Haggarty, K. M. Koeller, J. C. Wong, C. M. Grozinger, and S. L. Schreiber, "Domain-selective small-molecule inhibitor of histone deacetylase 6 (HDAC6)-mediated tubulin deacetylation," Proceedings of the National Academy of Sciences of the United States of America, vol. 100, no. 8, pp. 4389-4394, 2003.

[19] W. Weichert, "HDAC expression and clinical prognosis in human malignancies," Cancer Letters, vol. 280, no. 2, pp. 168176, 2009.

[20] R. N. Saha and K. Pahan, "HATs and HDACs in neurodegeneration: a tale of disconcerted acetylation homeostasis," Cell Death and Differentiation, vol. 13, no. 4, pp. 539-550, 2006. 
[21] K. L. Sugars and D. C. Rubinsztein, "Transcriptional abnormalities in Huntington disease," Trends in Genetics, vol. 19, no. 5, pp. 233-238, 2003.

[22] J. H. J. Cha, “Transcriptional dysregulation in Huntington's disease," Trends in Neurosciences, vol. 23, no. 9, pp. 387-392, 2000.

[23] J. S. Steffan, L. Bodai, J. Pallos et al., "Histone deacetylase inhibitors arrest polyglutamine-dependent neurodegeneration in Drosophila," Nature, vol. 413, no. 6857, pp. 739-743, 2001.

[24] A. McCampbell, A. A. Taye, L. Whitty, E. Penney, J. S. Steffan, and K. H. Fischbeck, "Histone deacetylase inhibitors reduce polyglutamine toxicity," Proceedings of the National Academy of Sciences of the United States of America, vol. 98, no. 26, pp. 15179-15184, 2001.

[25] R. J. Ferrante, J. K. Kubilus, J. Lee et al., "Histone deacetylase inhibition by sodium butyrate chemotherapy ameliorates the neurodegenerative phenotype in Huntington's disease mice," Journal of Neuroscience, vol. 23, no. 28, pp. 9418-9427, 2003.

[26] E. Hockly, V. M. Richon, B. Woodman et al., "Suberoylanilide hydroxamic acid, a histone deacetylase inhibitor, ameliorates motor deficits in a mouse model of Huntington's disease," Proceedings of the National Academy of Sciences of the United States of America, vol. 100, no. 4, pp. 2041-2046, 2003.

[27] H. Ryu, K. Smith, S. I. Camelo et al., "Sodium phenylbutyrate prolongs survival and regulates expression of anti-apoptotic genes in transgenic amyotrophic lateral sclerosis mice," Journal of Neurochemistry, vol. 93, no. 5, pp. 1087-1098, 2005.

[28] S. Petri, M. Kiaei, K. Kipiani et al., "Additive neuroprotective effects of a histone deacetylase inhibitor and a catalytic antioxidant in a transgenic mouse model of amyotrophic lateral sclerosis," Neurobiology of Disease, vol. 22, no. 1, pp. 40-49, 2006.

[29] S. Camelo, A. H. Iglesias, D. Hwang et al., "Transcriptional therapy with the histone deacetylase inhibitor trichostatin A ameliorates experimental autoimmune encephalomyelitis," Journal of Neuroimmunology, vol. 164, no. 1-2, pp. 10-21, 2005.

[30] J. G. Chang, H. M. Hsieh-Li, Y. J. Jong, N. M. Wang, C. H. Tsai, and H. Li, "Treatment of spinal muscular atrophy by sodium butyrate," Proceedings of the National Academy of Sciences of the United States of America, vol. 98, no. 17, pp. 9808-9813, 2001.

[31] A. M. Avila, B. G. Burnett, A. A. Taye et al., "Trichostatin A increases SMN expression and survival in a mouse model of spinal muscular atrophy," Journal of Clinical Investigation, vol. 117, no. 3, pp. 659-671, 2007.

[32] F. Yildirim, K. Gertz, G. Kronenberg et al., "Inhibition of histone deacetylation protects wildtype but not gelsolindeficient mice from ischemic brain injury," Experimental Neurology, vol. 210, no. 2, pp. 531-542, 2008.

[33] T. Lin, H. Chen, E. Koustova et al., "Histone deacetylase as therapeutic target in a rodent model of hemorrhagic shock: effect of different resuscitation strategies on lung and liver," Surgery, vol. 141, no. 6, pp. 784-794, 2007.

[34] W. Cao, C. Bao, E. Padalko, and C. J. Lowenstein, "Acetylation of mitogen-activated protein kinase phosphatase-1 inhibits Toll-like receptor signaling," Journal of Experimental Medicine, vol. 205, no. 6, pp. 1491-1503, 2008.

[35] L. Zhang, J. Wan, R. Jiang et al., "Protective effects of trichostatin A on liver injury in septic mice," Hepatology Research, vol. 39, no. 9, pp. 931-938, 2009.
[36] E. A. Sailhamer, Y. Li, E. J. Smith et al., "Acetylation: a novel method for modulation of the immune response following trauma/hemorrhage and inflammatory second hit in animals and humans," Surgery, vol. 144, no. 2, pp. 204-216, 2008.

[37] H. R. Champion, R. F. Bellamy, C. P. Roberts, and A. Leppaniemi, "A profile of combat injury," The Journal of Trauma, vol. 54, no. 5, pp. S13-S19, 2003.

[38] M. Valko, D. Leibfritz, J. Moncol, M. T. D. Cronin, M. Mazur, and J. Telser, "Free radicals and antioxidants in normal physiological functions and human disease," International Journal of Biochemistry and Cell Biology, vol. 39, no. 1, pp. 44-84, 2007.

[39] C. Shults, E. A. Sailhamer, Y. Li et al., "Surviving blood loss without fluid resuscitation," The Journal of Trauma, vol. 64, no. 3, pp. 629-638, 2008.

[40] E. Y. Fukudome, A. R. Kochanek, Y. Li et al., "Pharmacologic resuscitation promotes survival and attenuates hemorrhageinduced activation of extracellular signal-regulated kinase 1/2," Journal of Surgical Research. In press.

[41] H. B. Alam, F. Shuja, M. U. Butt et al., "Surviving blood loss without blood transfusion in a swine poly-trauma model," Surgery, vol. 146, no. 2, pp. 325-333, 2009.

[42] Y. Li, Z. Yuan, B. Liu et al., "Prevention of hypoxia-induced neuronal apoptosis through histone deacetylase inhibition," The Journal of Trauma, vol. 64, no. 4, pp. 863-870, 2008.

[43] H. Ryu, J. Lee, B. A. Olofsson et al., "Histone deacetylase inhibitors prevent oxidative neuronal death independent of expanded polyglutamine repeats via an Sp1-dependent pathway," Proceedings of the National Academy of Sciences of the United States of America, vol. 100, no. 7, pp. 4281-4286, 2003.

[44] K. T. Chang and K. T. Min, "Regulation of lifespan by histone deacetylase," Ageing Research Reviews, vol. 1, no. 3, pp. 313326, 2002.

[45] G. Faraco, T. Pancani, L. Formentini et al., "Pharmacological inhibition of histone deacetylases by suberoylanilide hydroxamic acid specifically alters gene expression and reduces ischemic injury in the mouse brain," Molecular Pharmacology, vol. 70, no. 6, pp. 1876-1884, 2006.

[46] C. Shults, E. A. Sailhamer, Y. Li et al., "Surviving blood loss without fluid resuscitation," The Journal of Trauma, vol. 64, no. 3, pp. 629-638, 2008.

[47] Y. Li, B. Liu, E. A. Sailhamer et al., "Cell protective mechanism of valproic acid in lethal hemorrhagic shock," Surgery, vol. 144, no. 2, pp. 217-224, 2008.

[48] A. Granger, I. Abdullah, F. Huebner et al., "Histone deacetylase inhibition reduces myocardial ischemia-reperfusion injury in mice," The FASEB Journal, vol. 22, no. 10, pp. 35493560, 2008.

[49] A. Krivoruchko and K. B. Storey, "Epigenetics in anoxia tolerance: a role for histone deacetylases," Molecular and Cellular Biochemistry. In press.

[50] E. R. Gonzales, H. Chen, R. M. Munuve, T. Mehrani, A. Nadel, and E. Koustova, "Hepatoprotection and lethality rescue by histone deacetylase inhibitor valproic acid in fatal hemorrhagic shock," The Journal of Trauma, vol. 65, no. 3, pp. 554-565, 2008.

[51] J. St-Pierre, S. Drori, M. Uldry et al., "Suppression of reactive oxygen species and neurodegeneration by the PGC-1 transcriptional coactivators," Cell, vol. 127, no. 2, pp. 397-408, 2006. 
[52] A. Kucharska, L. K. Rushworth, C. Staples, N. A. Morrice, and S. M. Keyse, "Regulation of the inducible nuclear dualspecificity phosphatase DUSP5 by ERK MAPK," Cellular Signalling, vol. 21, no. 12, pp. 1794-1805, 2009.

[53] T. Marumo, K. Hishikawa, M. Yoshikawa, and T. Fujita, "Epigenetic regulation of BMP7 in the regenerative response to ischemia," Journal of the American Society of Nephrology, vol. 19, no. 7, pp. 1311-1320, 2008.

[54] N. Zacharias, E. A. Sailhamer, Y. Li et al., "Histone deacetylase inhibitors prevent apoptosis following lethal hemorrhagic shock in rodent kidney cells," Resuscitation, vol. 82, no. 1, pp. 105-109, 2011.

[55] G. Y. Oudit, H. Sun, B. G. Kerfant, M. A. Crackower, J. M. Penninger, and P. H. Backx, "The role of phosphoinositide-3 kinase and PTEN in cardiovascular physiology and disease," Journal of Molecular and Cellular Cardiology, vol. 37, no. 2, pp. 449-471, 2004.

[56] F. Shuja, M. Tabbara, Y. Li et al., "Profound hypothermia decreases cardiac apoptosis through Akt survival pathway," Journal of the American College of Surgeons, vol. 209, no. 1, pp. 89-99, 2009.

[57] A. J. Kim, Y. Shi, R. C. Austin, and G. H. Werstuck, "Valproate protects cells fom ER stress-induced lipid accumulation and apoptosis by inhibiting glycogen synthase kinase-3," Journal of Cell Science, vol. 118, no. 1, pp. 89-99, 2005.

[58] X. H. Yao and B. L. Nyomba, "Hepatic insulin resistance induced by prenatal alcohol exposure is associated with reduced PTEN and TRB3 acetylation in adult rat offspring," American Journal of Physiology, vol. 294, no. 6, pp. R1797R1806, 2008.

[59] D. Torella, M. Rota, D. Nurzynska et al., "Cardiac stem cell and myocyte aging, heart failure, and insulin-like growth factor-1 overexpression," Circulation Research, vol. 94, no. 4, pp. 514-524, 2004.

[60] A. Chesley, M. S. Lundberg, T. Asai et al., "The $\beta$-adrenergic receptor delivers an antiapoptotic signal to cardiac myocytes through $\mathrm{G}_{\mathrm{i}}$-dependent coupling to phosphatidylinositol 3'kinase," Circulation Research, vol. 87, no. 12, pp. 1172-1179, 2000.

[61] K. H. Kim, G. Y. Oudit, and P. H. Backx, "Erythropoietin protects against doxorubicin-induced cardiomyopathy via a phosphatidylinositol 3-kinase-dependent pathway," Journal of Pharmacology and Experimental Therapeutics, vol. 324, no. 1, pp. 160-169, 2008.

[62] B. DeBosch, N. Sambandam, C. Weinheimer, M. Courtois, and A. J. Muslin, "Akt2 regulates cardiac metabolism and cardiomyocyte survival," Journal of Biological Chemistry, vol. 281, no. 43, pp. 32841-32851, 2006.

[63] J. Avery, S. Etzion, B. J. Debosch et al., "TRB3 function in cardiac endoplasmic reticulum stress," Circulation Research, vol. 106, no. 9, pp. 1516-1523, 2010.

[64] H. Kishimoto, K. Hamada, M. Saunders et al., "Physiological functions of Pten in mouse tissues," Cell Structure and Function, vol. 28, no. 1, pp. 11-21, 2003.

[65] G. Schwartzbauer and J. Robbins, "The tumor suppressor gene PTEN can regulate cardiac hypertrophy and survival," Journal of Biological Chemistry, vol. 276, no. 38, pp. 3578635793, 2001.

[66] J. O. Lee, H. Yang, M. M. Georgescu et al., "Crystal structure of the PTEN tumor suppressor: implications for its phosphoinositide phosphatase activity and membrane association," Cell, vol. 99, no. 3, pp. 323-334, 1999.
[67] T. Maehama and J. E. Dixon, "The tumor suppressor, PTEN/MMAC1, dephosphorylates the lipid second messenger, phosphatidylinositol 3,4,5-trisphosphate," Journal of Biological Chemistry, vol. 273, no. 22, pp. 13375-13378, 1998.

[68] V. Stambolic, A. Suzuki, J. L. de la Pompa et al., "Negative regulation of $\mathrm{PKB} / \mathrm{Akt}$-dependent cell survival by the tumor suppressor PTEN," Cell, vol. 95, no. 1, pp. 29-39, 1998.

[69] B. Stiles, M. Groszer, S. Wang, J. Jiao, and H. Wu, "PTENless means more," Developmental Biology, vol. 273, no. 2, pp. 175184, 2004.

[70] K. Okumura, M. Mendoza, R. M. Bachoo, R. A. DePinho, W. K. Cavenee, and F. B. Furnari, "PCAF modulates PTEN activity," Journal of Biological Chemistry, vol. 281, no. 36, pp. 26562-26568, 2006.

[71] T. Tamguney and D. Stokoe, "New insights into PTEN," Journal of Cell Science, vol. 120, no. 23, pp. 4071-4079, 2007.

[72] K. Du, S. Herzig, R. N. Kulkarni, and M. Montminy, "TRB3: a tribbles homolog that inhibits Akt/PKB activation by insulin in liver," Science, vol. 300, no. 5625, pp. 1574-1577, 2003.

[73] A. R. Saltiel, "Putting the brakes on insulin signaling," The New England Journal of Medicine, vol. 349, no. 26, pp. 25602562, 2003.

[74] Z. Marinova, M. Ren, J. R. Wendland et al., "Valproic acid induces functional heat-shock protein 70 via class I histone deacetylase inhibition in cortical neurons: a potential role of Sp1 acetylation," Journal of Neurochemistry, vol. 111, no. 4, pp. 976-987, 2009.

[75] T. Gao and A. C. Newton, "The turn motif is a phosphorylation switch that regulates the binding of Hsp70 to protein kinase C," Journal of Biological Chemistry, vol. 277, no. 35, pp. 31585-31592, 2002.

[76] T. Gotoh, K. Terada, S. Oyadomari, and M. Mori, "hsp70DnaJ chaperone pair prevents nitric oxide- and CHOPinduced apoptosis by inhibiting translocation of Bax to mitochondria," Cell Death and Differentiation, vol. 11, no. 4, pp. 390-402, 2004.

[77] A. R. Stankiewicz, G. Lachapelle, C. P. Z. Foo, S. M. Radicioni, and D. D. Mosser, "Hsp70 inhibits heat-induced apoptosis upstream of mitochondria by preventing Bax translocation," Journal of Biological Chemistry, vol. 280, no. 46, pp. 38729-38739, 2005.

[78] H. M. Beere, B. B. Wolf, K. Cain et al., "Heat-shock protein 70 inhibits apoptosis by preventing recruitment of procaspase- 9 to the Apaf-1 apoptosome," Nature Cell Biology, vol. 2, no. 8, pp. 469-475, 2000.

[79] A. Saleh, S. M. Srinivasula, L. Balkir, P. D. Robbins, and E. S. Alnemri, "Negative regulation of the Apaf-1 apoptosome by Hsp70," Nature Cell Biology, vol. 2, no. 8, pp. 476-483, 2000.

[80] M. Jäättelä, D. Wissing, K. Kokholm, T. Kallunki, and M. Egeblad, "Hsp7O exerts its anti-apoptotic function downstream of caspase-3-like proteases," The EMBO Journal, vol. 17, no. 21, pp. 6124-6134, 1998.

[81] D. D. Mosser, A. W. Caron, L. Bourget et al., "The chaperone function of hsp70 is required for protection against stressinduced apoptosis," Molecular and Cellular Biology, vol. 20, no. 19, pp. 7146-7159, 2000.

[82] A. B. Meriin, J. A. Yaglom, V. L. Gabai, D. D. Mosser, L. Zon, and M. Y. Sherman, "Protein-damaging stresses activate cJun N-terminal kinase via inhibition of its dephosphorylation: a novel pathway controlled by HSP72," Molecular and Cellular Biology, vol. 19, no. 4, pp. 2547-2555, 1999.

[83] V. Volloch, V. L. Gabai, S. Rits, and M. Y. Sherman, "ATPase activity of the heat shock protein Hsp72 is dispensable for its effects on dephosphorylation of stress kinase JNK and on 
heat-induced apoptosis," FEBS Letters, vol. 461, no. 1-2, pp. 73-76, 1999.

[84] H. S. Park, S. G. Cho, C. K. Kim et al., "Heat shock protein $\mathrm{Hsp} 72$ is a negative regulator of apoptosis signal-regulating kinase 1," Molecular and Cellular Biology, vol. 22, no. 22, pp. 7721-7730, 2002.

[85] A. L. Joly, G. Wettstein, G. Mignot, F. Ghiringhelli, and C. Garrido, "Dual role of heat shock proteins as regulators of apoptosis and innate immunity," Journal of Innate Immunity, vol. 2, no. 3, pp. 238-247, 2010.

[86] E. A. Deitch, "Role of the gut lymphatic system in multiple organ failure," Current Opinion in Critical Care, vol. 7, no. 2, pp. 92-98, 2001.

[87] E. A. Deitch, D. Xu, and V. L. Kaiser, "Role of the gut in the development of injury- and shock induced SIRS and MODS: the gut-lymph hypothesis, a review," Frontiers in Bioscience, vol. 11, no. 1, pp. 520-528, 2006.

[88] A. B. Peitzman, B. G. Harbrecht, A. O. Udekwu, T. R. Billiar, E. Kelly, and R. L. Simmons, "Hemorrhagic shock," Current Problems in Surgery, vol. 32, no. 11, pp. 925-1002, 1995.

[89] G. Thuijls, J. J. De Haan, J. P. M. Derikx et al., "Intestinal cytoskeleton degradation precedes tight junction loss following hemorrhagic shock," Shock, vol. 31, no. 2, pp. 164-169, 2009.

[90] E. A. Deitch, "Multiple organ failure: pathophysiology and potential future therapy," Annals of Surgery, vol. 216, no. 2, pp. 117-134, 1992.

[91] H. T. Hassoun, B. C. Kone, D. W. Mercer, F. G. Moody, N. W. Weisbrodt, and F. A. Moore, "Post-injury multiple organ failure: the role of the gut," Shock, vol. 15, no. 1, pp. 1-10, 2001.

[92] V. Wong and B. M. Gumbiner, "Synthetic peptide corresponding to the extracellular domain of occludin perturbs the tight junction permeability barrier," Journal of Cell Biology, vol. 136, no. 2, pp. 399-409, 1997.

[93] J. W. Baker, E. A. Deitch, M. Li, R. D. Berg, and R. D. Specian, "Hemorrhagic shock induces bacterial translocation from the gut," The Journal of Trauma, vol. 28, no. 7, pp. 896-906, 1988.

[94] M. P. Fink and R. L. Delude, "Epithelial barrier dysfunction: a unifying theme to explain the pathogenesis of multiple organ dysfunction at the cellular level," Critical Care Clinics, vol. 21, no. 2, pp. 177-196, 2005.

[95] C. Hierholzer and T. R. Billiar, "Molecular mechanisms in the early phase of hemorrhagic shock," Langenbeck's Archives of Surgery, vol. 386, no. 4, pp. 302-308, 2001.

[96] P. J. Morin, "Claudin proteins in human cancer: promising new targets for diagnosis and therapy," Cancer Research, vol. 65, no. 21, pp. 9603-9606, 2005.

[97] Y. Li, B. Liu, S. T. Dillon et al., "Identification of a novel potential biomarker in a model of hemorrhagic shock and valproic acid treatment," Journal of Surgical Research, vol. 159, no. 1, pp. 474-481, 2010.

[98] A. R. Kochenek, E. Y. Fukudome, J. S. Eleanor et al., "Pharmacological resuscitation attenuates MAP kinase pathway activation and pulmonary inflammation following hemorrhagic shock in rodent model," in Proceedings of the Annual Meeting of the American College of Surgenones, October 2010.

[99] F. Blanchard and C. Chipoy, "Histone deacetylase inhibitors: new drugs for the treatment of inflammatory diseases?" Drug Discovery Today, vol. 10, no. 3, pp. 197-204, 2005.
[100] F. Leoni, G. Fossati, E. C. Lewis et al., "The histone deacetylase inhibitor ITF2357 reduces production of proinflammatory cytokines in vitro and systemic inflammation in vivo," Molecular Medicine, vol. 11, no. 1-12, pp. 1-15, 2005.

[101] Y. Li, B. Liu, E. Y. Fukudome et al., "Surviving lethal septic shock without fluid resuscitation in a rodent model," Surgery, vol. 148, no. 2, pp. 246-254, 2010.

[102] L. Zhang, S. Jin, C. Wang, R. Jiang, and J. Wan, "Histone deacetylase inhibitors attenuate acute lung injury during cecal ligation and puncture-induced polymicrobial sepsis," World Journal of Surgery, pp. 1-8, 2010.

[103] M. S. Hayden and S. Ghosh, "Shared Principles in NF- $\kappa$ B Signaling," Cell, vol. 132, no. 3, pp. 344-362, 2008.

[104] W. G. Deng and K. K. Wu, "Regulation of Inducible Nitric Oxide Synthase Expression by p300 and p50 Acetylation," Journal of Immunology, vol. 171, no. 12, pp. 6581-6588, 2003.

[105] WU. G. Deng, Y. Zhu, and K. K. Wu, "Up-regulation of p300 binding and p50 acetylation in tumor necrosis factor$\alpha$-induced cyclooxygenase- 2 promoter activation," Journal of Biological Chemistry, vol. 278, no. 7, pp. 4770-4777, 2003.

[106] L. F. Chen and W. C. Greene, "Shaping the nuclear action of NF- $\kappa$ B," Nature Reviews Molecular Cell Biology, vol. 5, no. 5, pp. 392-401, 2004.

[107] L. F. Chen, Y. Mu, and W. C. Greene, "Acetylation of RelA at discrete sites regulates distinct nuclear functions of NF- $\kappa \mathrm{B}$," The EMBO Journal, vol. 21, no. 23, pp. 6539-6548, 2002.

[108] R. Kiernan, V. Brès, R. W. M. Ng et al., "Post-activation turn-off of NF- $\kappa \mathrm{B}$-dependent transcription is regulated by acetylation of p65," Journal of Biological Chemistry, vol. 278, no. 4, pp. 2758-2766, 2003.

[109] N. Huang, J. P. Katz, D. R. Martin, and G. D. Wu, "Inhibition of IL-8 gene expression in Caco-2 cells by compounds which induce histone hyperacetylation," Cytokine, vol. 9, no. 1, pp. 27-36, 1997.

[110] M. S. Inan, R. J. Rasoulpour, L. Yin, A. K. Hubbard, D. W. Rosenberg, and C. Giardina, "The luminal short-chain fatty acid butyrate modulates NF- $\kappa \mathrm{B}$ activity in a human colonic epithelial cell line," Gastroenterology, vol. 118, no. 4, pp. 724734, 2000.

[111] O. H. Krämer, M. Göttlicher, and T. Heinzel, "Histone deacetylase as a therapeutic target," Trends in Endocrinology and Metabolism, vol. 12, no. 7, pp. 294-300, 2001.

[112] E. Adam, V. Quivy, F. Bex et al., "Potentiation of tumor necrosis factor-induced NF- $\kappa$ B activation by deacetylase inhibitors is associated with a delayed cytoplasmic reappearance of $\mathrm{I} \kappa \mathrm{B} \alpha$," Molecular and Cellular Biology, vol. 23, no. 17, pp. 6200-6209, 2003.

[113] B. P. Ashburner, S. D. Westerheide, and A. S. Baldwin, "The p65 (RelA) subunit of NF- $\kappa \mathrm{B}$ interacts with the histone deacetylase (HDAC) corepressors HDAC1 and HDAC2 to negatively regulate gene expression," Molecular and Cellular Biology, vol. 21, no. 20, pp. 7065-7077, 2001.

[114] V. Quivy, E. Adam, Y. Collette et al., "Synergistic activation of human immunodeficiency virus type 1 promoter activity by NF- $\kappa \mathrm{B}$ and inhibitors of deacetylases: potential perspectives for the development of therapeutic strategies," Journal of Virology, vol. 76, no. 21, pp. 11091-11103, 2002.

[115] W. V. Berghe, K. De Bosscher, E. Boone, S. Plaisance, and G. Haegeman, "The nuclear factor- $\kappa \mathrm{B}$ engages $\mathrm{CBP} / \mathrm{p} 300$ and histone acetyltransferase activity for transcriptional activation of the interleukin-6 gene promoter," Journal of Biological Chemistry, vol. 274, no. 45, pp. 32091-32098, 1999.

[116] S. Thomson, A. L. Clayton, C. A. Hazzalin, S. Rose, M. J. Barratt, and L. C. Mahadevan, "The nucleosomal response 
associated with immediate-early gene induction is mediated via alternative MAP kinase cascades: MSK1 as a potential histone H3/HMG-14 kinase," The EMBO Journal, vol. 18, no. 17, pp. 4779-4793, 1999.

[117] S. Saccani, S. Pantano, and G. Natoli, "p38-dependent marking of inflammatory genes for increased NF- $\kappa$ B recruitment," Nature Immunology, vol. 3, no. 1, pp. 69-75, 2002.

[118] H. Chi and R. A. Flavell, "Acetylation of MKP-1 and the control of inflammation," Science Signaling, vol. 1, no. 41, p. pe44, 2008.

[119] T. J. Murphy, H. M. Paterson, J. A. Mannick, and J. A. Lederer, "Injury, sepsis, and the regulation of Toll-like receptor responses," Journal of Leukocyte Biology, vol. 75, no. 3, pp. 400-407, 2004.

[120] A. J. Botha, F. A. Moore, E. E. Moore, A. Sauaia, A. Banerjee, and V. M. Peterson, "Early neutrophil sequestration after injury: a pathogenic mechanism for multiple organ failure," The Journal of Trauma, vol. 39, no. 3, pp. 411-417, 1995.

[121] A. M. Winter-Vann and G. L. Johnson, "Integrated activation of MAP3Ks balances cell fate in response to stress," Journal of Cellular Biochemistry, vol. 102, no. 4, pp. 848-858, 2007.

[122] N. D. Perkins, "Integrating cell-signalling pathways with NF$\kappa \mathrm{B}$ and IKK function," Nature Reviews Molecular Cell Biology, vol. 8, no. 1, pp. 49-62, 2007.

[123] M. E. Bianchi, "DAMPs, PAMPs and alarmins: all we need to know about danger," Journal of Leukocyte Biology, vol. 81, no. 1, pp. 1-5, 2007.

[124] M. F. Tsan and B. Gao, "Heat shock proteins and immune system," Journal of Leukocyte Biology, vol. 85, no. 6, pp. 905910, 2009.

[125] T. H. Rogers and J. E. Babensee, "Altered adherent leukocyte profile on biomaterials in Toll-like receptor 4 deficient mice," Biomaterials, vol. 31, no. 4, pp. 594-601, 2010.

[126] U. Mahlknecht, J. Will, A. Varin, D. Hoelzer, and G. Herbein, "Histone deacetylase 3, a class I histone deacetylase, suppresses MAPK11-mediated activating transcription factor2 activation and represses TNF gene expression," Journal of Immunology, vol. 173, no. 6, pp. 3979-3990, 2004.

[127] M. Wetzel, D. R. D. Premkumar, B. Arnold, and I. F. Pollack, "Effect of trichostatin A, a histone deacetylase inhibitor, on glioma proliferation in vitro by inducing cell cycle arrest and apoptosis," Journal of Neurosurgery, vol. 103, supplement 6, pp. 549-556, 2005.

[128] H. T. Aung, K. Schroder, S. R. Himes et al., "LPS regulates proinflammatory gene expression in macrophages by altering histone deacetylase expression," The FASEB Journal, vol. 20, no. 9, pp. 1315-1327, 2006.

[129] S. B. Han and J. K. Lee, "Anti-inflammatory effect of trichostatin-A on murine bone marrow-derived macrophages," Archives of Pharmacal Research, vol. 32, no. 4, pp. 613-624, 2009.

[130] T. Suuronen, J. Huuskonen, R. Pihlaja, S. Kyrylenko, and A. Salminen, "Regulation of microglial inflammatory response by histone deacetylase inhibitors," Journal of Neurochemistry, vol. 87, no. 2, pp. 407-416, 2003.

[131] Y. Choi, S. K. Park, M. K. Hwan et al., "Histone deacetylase inhibitor KBH-A42 inhibits cytokine production in RAW 264.7 macrophage cells and in vivo endotoxemia model," Experimental and Molecular Medicine, vol. 40, no. 5, pp. 574581, 2008.

[132] W. K. Kelly and P. A. Marks, "Drug insight: histone deacetylase inhibitors-development of the new targeted anticancer agent suberoylanilide hydroxamic acid," Nature Clinical Practice Oncology, vol. 2, no. 3, pp. 150-157, 2005.
[133] M. Dokmanovic, C. Clarke, and P. A. Marks, "Histone deacetylase inhibitors: overview and perspectives," Molecular Cancer Research, vol. 5, no. 10, pp. 981-989, 2007.

[134] J. S. Ungerstedt, Y. Sowa, W. S. Xu et al., "Role of thioredoxin in the response of normal and transformed cells to histone deacetylase inhibitors," Proceedings of the National Academy of Sciences of the United States of America, vol. 102, no. 3, pp. 673-678, 2005.

[135] C. H. Lillig and A. Holmgren, "Thioredoxin and related molecules-from biology to health and disease," Antioxidants and Redox Signaling, vol. 9, no. 1, pp. 25-47, 2007.

[136] L. M. Butler, X. Zhou, W. S. Xu et al., "The histone deacetylase inhibitor SAHA arrests cancer cell growth, upregulates thioredoxin-binding protein-2, and down-regulates thioredoxin," Proceedings of the National Academy of Sciences of the United States of America, vol. 99, no. 18, pp. 1170011705, 2002.

[137] M. Saitoh, H. Nishitoh, M. Fujii et al., "Mammalian thioredoxin is a direct inhibitor of apoptosis signal-regulating kinase (ASK) 1," The EMBO Journal, vol. 17, no. 9, pp. 25962606, 1998

[138] A. Lai, J. M. Lee, W. M. Yang et al., "RBP1 recruits both histone deacetylase-dependent and -independent repression activities to retinoblastoma family proteins," Molecular and Cellular Biology, vol. 19, no. 10, pp. 6632-6641, 1999.

[139] J. Kaczynski, J. S. Zhang, V. Ellenrieder et al., "The Sp1like protein BTEB3 inhibits transcription via the basic transcription element box by interacting with $\mathrm{mSin} 3 \mathrm{~A}$ and HDAC-1 co-repressors and competing with Sp1," Journal of Biological Chemistry, vol. 276, no. 39, pp. 36749-36756, 2001.

[140] Z. Yu, W. Zhang, and B. C. Kone, "Histone deacetylases augment cytokine induction of the iNOS gene," Journal of the American Society of Nephrology, vol. 13, no. 8, pp. 2009-2017, 2002.

[141] S. C. Tsai, N. Valkov, W. M. Yang, J. Gump, D. Sullivan, and E. Seto, "Histone deacetylase interacts directly with DNA topoisomerase II," Nature Genetics, vol. 26, no. 3, pp. 349-353, 2000.

[142] H. Zhu, L. Shan, P. W. Schiller, A. Mai, and T. Peng, "Histone deacetylase- 3 activation promotes tumor necrosis factor- $\alpha$ (TNF- $\alpha$ ) expression in cardiomyocytes during lipopolysaccharide stimulation," Journal of Biological Chemistry, vol. 285, no. 13, pp. 9429-9436, 2010.

[143] C. M. Grozinger and S. L. Schreiber, "Regulation of histone deacetylase 4 and 5 and transcriptional activity by 14-3-3dependent cellular localization," Proceedings of the National Academy of Sciences of the United States of America, vol. 97, no. 14, pp. 7835-7840, 2000.

[144] F. Yeung, J. E. Hoberg, C. S. Ramsey et al., "Modulation of NF- $\kappa \mathrm{B}$-dependent transcription and cell survival by the SIRT1 deacetylase," The EMBO Journal, vol. 23, no. 12, pp. 2369-2380, 2004.

[145] S. Spange, T. Wagner, T. Heinzel, and O. H. Krämer, "Acetylation of non-histone proteins modulates cellular signalling at multiple levels," International Journal of Biochemistry and Cell Biology, vol. 41, no. 1, pp. 185-198, 2009.

[146] M. A. Wilson, A. R. Ricci, B. J. Deroo, and T. K. Archer, "The histone deacetylase inhibitor trichostatin A blocks progesterone receptor-mediated transactivation of the mouse mammary tumor virus promoter in vivo," Journal of Biological Chemistry, vol. 277, no. 17, pp. 15171-15181, 2002. 

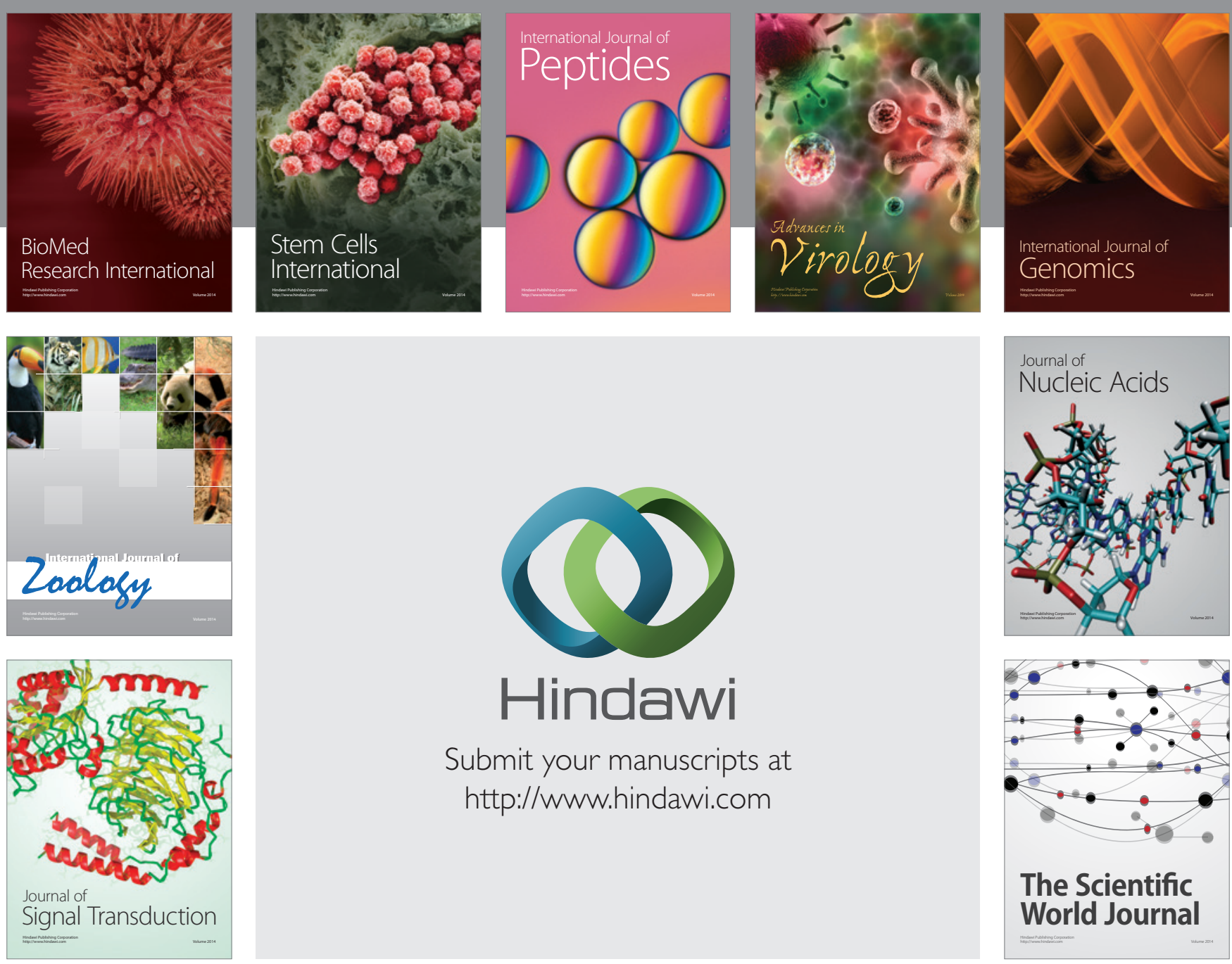

Submit your manuscripts at

http://www.hindawi.com
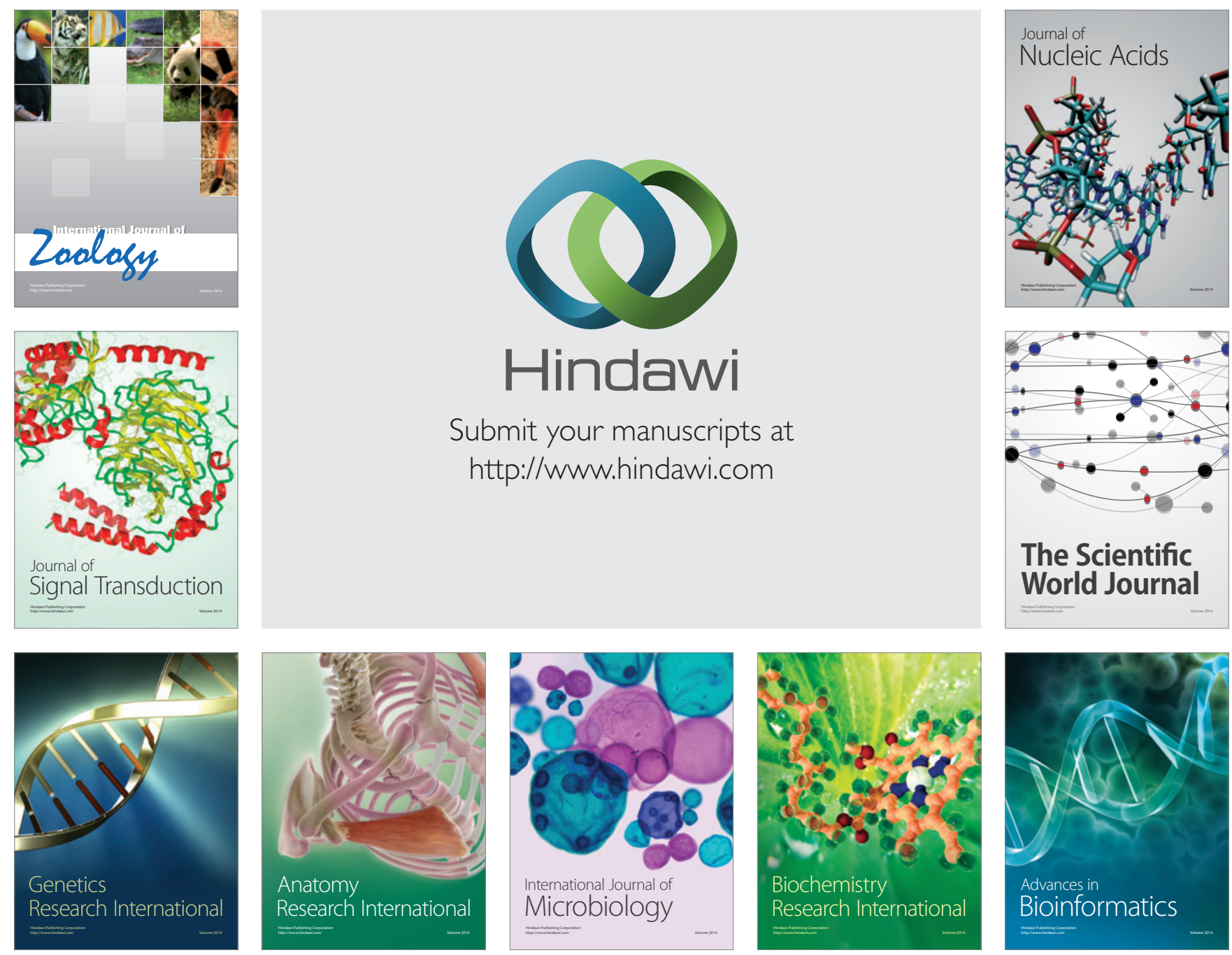

The Scientific World Journal
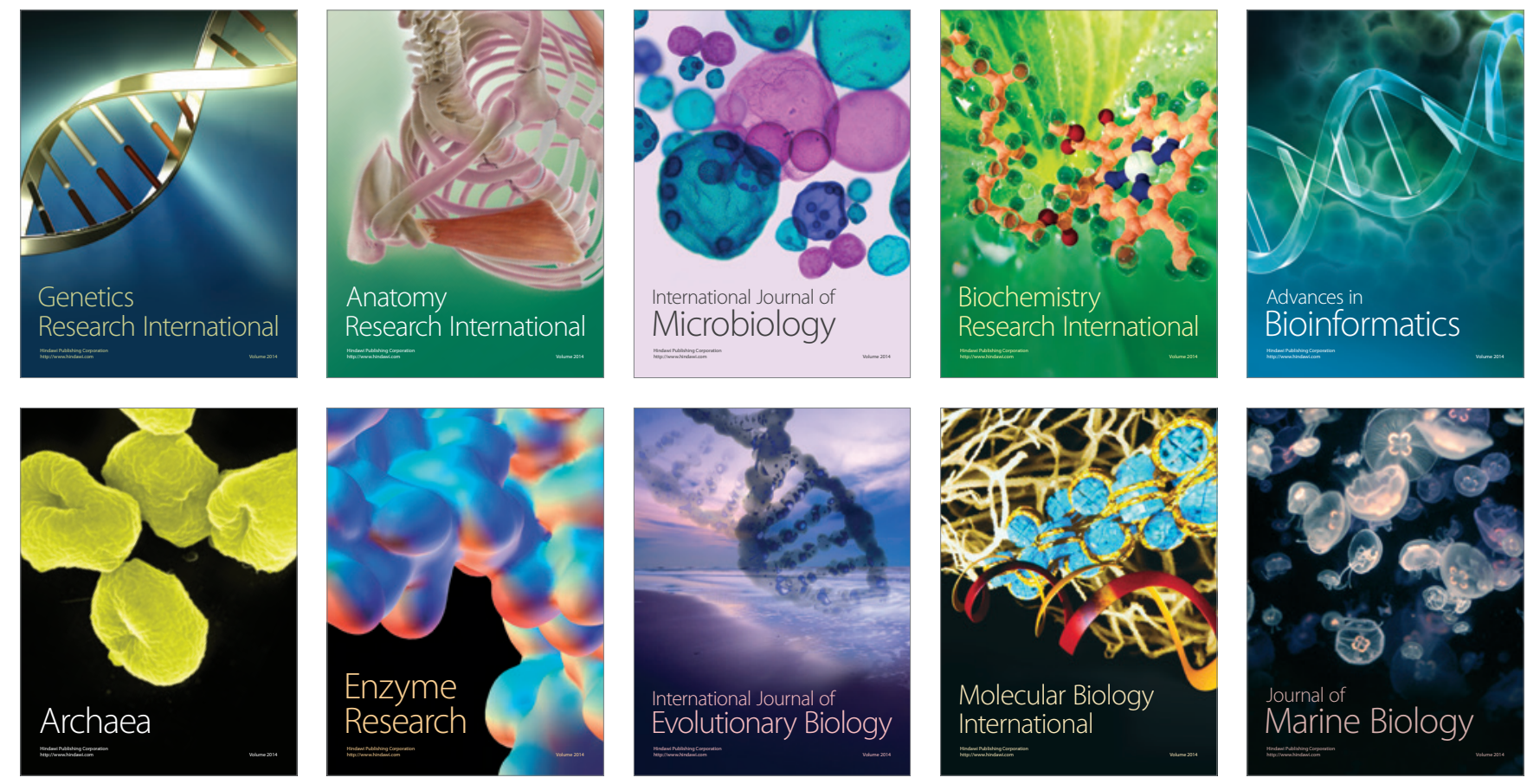